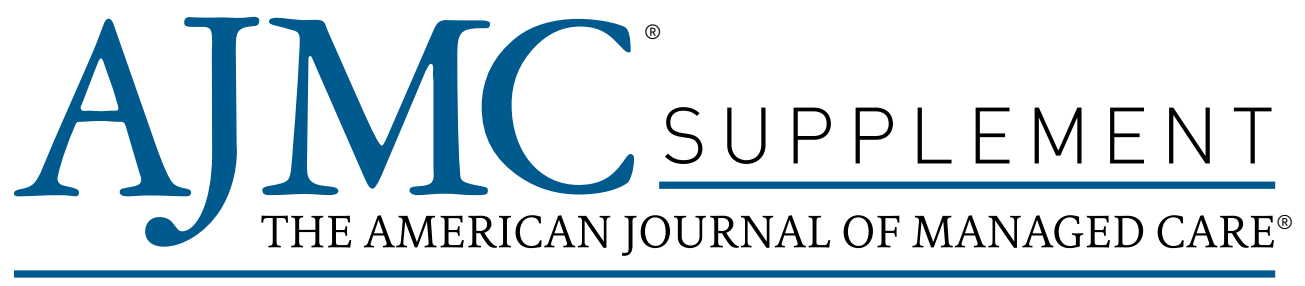

\title{
Management of TRK
}

\section{Fusion Cancer: Evaluating Targeted Therapies}

\section{HIGHLIGHTS}

> Diagnosis and Management of TRK Fusion Cancer

> Comparative Effectiveness of Larotrectinib and Entrectinib for TRK Fusion Cancer 


\section{Management of TRK Fusion Cancer: Evaluating Targeted Therapies}

This supplement was financially supported by Bayer HealthCare Pharmaceuticals, Inc. 


\section{Management of TRK Fusion Cancer: Evaluating Targeted Therapies}

\section{OVERVIEW}

This supplement to The American Journal of Managed Care ${ }^{\circledR}$ describes the role and epidemiology of neurotrophic tyrosine receptor kinase (NTRK) gene fusions in cancer, explores the therapeutic benefits of targeting tropomyosin receptor kinase (TRK) fusions with small molecule inhibitors, reviews recommendations for NTRK gene fusion testing to guide treatment decisions, and examines the comparative effectiveness of the TRK inhibitors larotrectinib and entrectinib.

\section{TABLE OF CONTENTS}

Participating Faculty

\section{Reports}

Diagnosis and Management of TRK Fusion Cancer

Shivaani Kummar, MD, FACP; Antoine Italiano, $M D$, PhD; Marcia S. Brose, $M D, P h D$ Josh J. Carlson, PhD, MPH; Sean D. Sullivan, PhD, MSc, RPh; Ulrik Lassen, MD, PhD; Noah Federman, $M D$

Comparative Effectiveness of Larotrectinib and Entrectinib for TRK Fusion Cancer

Josh J. Carlson, PhD, MPH; Antoine Italiano, MD, PhD; Marcia S. Brose, MD, PhD; Noah Federman, MD; Ulrik Lassen, $M D$, PhD; Shivaani Kummar, MD, FACP.

Sean D. Sullivan, $P h D, M S c, R P h$ 


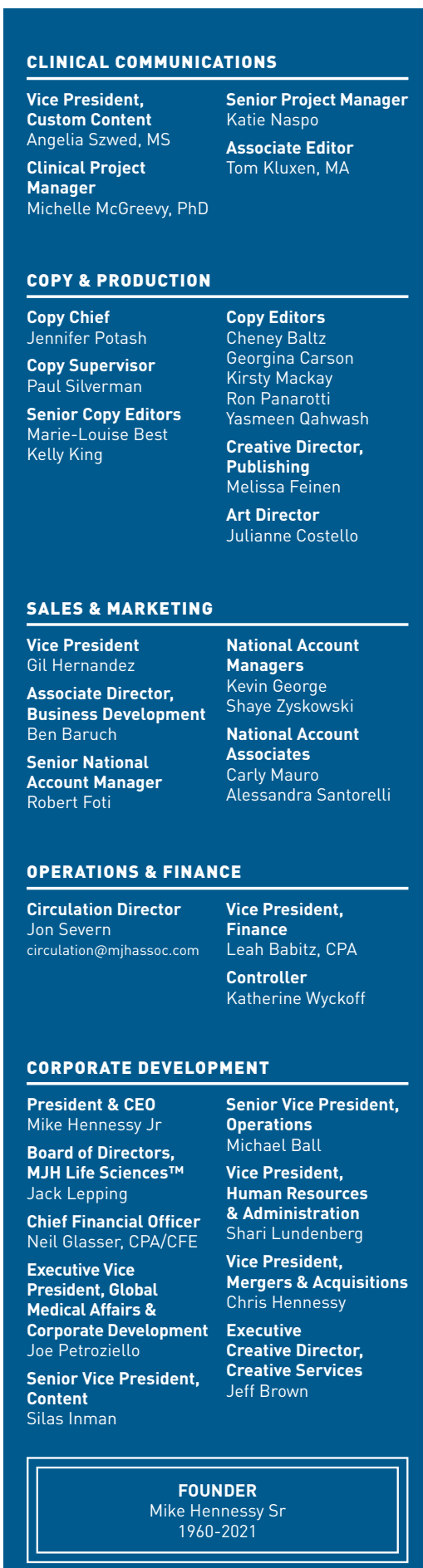

Copyright $\odot 2022$ by Managed Care \& Healthcare Communications, LLC

AN 1 - life sciences" BRAND

\section{PARTICIPATING FACULTY}

Marcia S. Brose, MD, PhD

Director of Cancer Services

Sidney Kimmel Cancer Center

Thomas Jefferson University Hospitals

Philadelphia, PA

\section{Josh J. Carlson, PhD, MPH}

Associate Professor

CHOICE Institute, School of Pharmacy

University of Washington

Seattle, WA

\section{Noah Federman, MD}

Clinical Professor

Director, Pediatric Bone and Soft Tissue

Sarcoma Program

David Geffen School of Medicine

University of California, Los Angeles

Los Angeles, CA

Antoine Italiano, MD, PhD

Professor

Early Phase Trials and Sarcoma Units

Institut Bergonié

Bordeaux, France
Shivaani Kummar, MD, FACP

DeArmond Endowed Chair of Cancer Research

Professor and Head, Division of Hematology and Medical Oncology

Codirector, Center for Experimental Therapeutics

Knight Cancer Institute

Oregon Health and Science University

Portland, OR

\section{Utrik Lassen, MD, PhD}

Professor of Clinical Oncology

Department of Oncology

Rigshospitalet

Copenhagen, Denmark

Sean D. Sullivan, PhD, MSc, RPh

Dean and Professor of Pharmacy

School of Pharmacy

Hutchinson Institute for Cancer

Outcomes Research

Fred Hutchinson Cancer Research Center

University of Washington

Seattle, WA

\section{FACULTY DISCLOSURES}

These faculty have disclosed the following relevant commercial financial relationships or affiliations in the past 12 months.

\section{Marcia S. Brose, MD, PhD}

CONSULTANCIES OR PAID ADVISORY BOARDS AstraZeneca, Bayer, Eli Lilly and Company, Genentech, Loxo Oncology

\section{HONORARIA}

Clinical Care Options, Medscape,

OncLive ${ }^{\circledR}$, PeerView

INSTITUTIONAL CONFLICTS OF INTEREST

Research support to the University of

Pennsylvania School of Pharmacy from

Bayer, Blueprint Medicines, Eisai, Eli Lilly and Company, Genentech, Loxo Oncology, Novartis

\section{Josh J. Carlson, PhD, MPH}

CONSULTANCIES OR PAID ADVISORY BOARDS Bayer

HONORARIA

Adaptive Biotechnologies

\section{Noah Federman, MD}

CONSULTANTIES OR PAID ADVISORY BOARDS Bayer, Loxo Oncology

\section{GRANTS RECEIVED}

Research is supported by NIH National Center for Advancing Translational Science (NCATS) UCLA Clinical \& Translational Science Institute (CTSI) Grant Number UL1TR001881

LECTURE FEES FOR SPEAKING AT THE INVITATION OF A COMMERCIAL SPONSOR Bayer

ROYALTIES

NanoValent Pharmaceuticals, Inc

STOCK OWNERSHIP

Stock held in for-profit health care companies bluebird bio, Inc, Genmab, Reata Pharmaceuticals
Antoine Italiano, MD, PhD

GRANTS RECEIVED

AstraZeneca, Bayer, Merck, Merck Sharp \& Dohme, PharmaMar, Roche

HONORARIA

Bayer, Daiichi Sankyo, Epizyme, Ipsen,

Roche, SpringWorks Therapeutics

\section{Shivaani Kummar, MD, FACP}

CONSULTANCIES OR PAID ADVISORY BOARDS Bayer, Boehringer Ingelheim, EcoR1 Capital, Genome \& Company, Gilead, Harbour Biomed, Seagen, SpringWorks Therapeutics, Mirati

Therapeutics, Mundipharma

STOCK OWNERSHIP

Cofounder and equity holder for PathomIQ OTHER

Editor-in-chief of Current Problems in Cancer (Elsevier); spouse is a scientific adviser for Cadila Pharmaceuticals Ltd and founder of Arxeon, Inc

\section{Ulrik Lassen, MD, PhD}

CONSULTANCIES OR PAID ADVISORY BOARDS Bayer, Novartis, Pfizer

GRANTS RECEIVED

Bristol Myers Squibb, GlaxoSmithKline, Pfizer, Roche

Sean D. Sullivan, PhD, MSc, RPh CONSULTANCIES OR PAID ADVISORY BOARDS Bayer 


\title{
Diagnosis and Management of TRK Fusion Cancer
}

\author{
Shivaani Kummar, MD, FACP; Antoine Italiano, MD, PhD; Marcia S. Brose, MD, PhD; \\ Josh J. Carlson, PhD, MPH; Sean D. Sullivan, PhD, MSc, RPh; Ulrik Lassen, MD, PhD; \\ Noah Federman, MD
}

\section{Overview of NTRK Gene Fusions}

The neurotrophic tyrosine receptor kinase (NTRK) genes NTRK1, NTRK2, and NTRK3 encode the tropomyosin receptor kinase (TRK) family of proteins: TRKA, TRKB, and TRKC, respectively. ${ }^{1}$ Neurotrophins were initially identified as survival factors for sensory and sympathetic neurons, but they are now understood to play many roles in the development and functioning of the nervous system..$^{1-3}$ TRK receptors are predominantly expressed in neuronal tissue, and their activation has a significant impact on a variety of neuronal events, such as cell differentiation and survival, proliferation, and synaptic formation. ${ }^{1,3}$ The precise regulation of TRK receptors and their activation is therefore critically important for normal cell functioning.

NTRK gene fusion events that occur between NTRK1, NTRK2, or NTRK3 and various unrelated gene partners have been identified in cancer. These typically arise from fusion of the 3' region of an NTRK gene (containing a functional kinase domain) and the 5 ' region of an unrelated gene, either by intra- or interchromosomal rearrangement. The resulting chimeric oncogenic gene fusion encodes a protein containing the $\mathrm{N}$-terminus of the fusion partner joined to the $\mathrm{C}$-terminus of the TRK protein, including the catalytic tyrosine kinase domain. This results in a protein that retains kinase activity, is ligand independent, and is constitutively activated to drive cell and tumor development. ${ }^{1,4}$ One of the most common and best characterized NTRK gene fusions is ETV6-NTRK3 (Figure 1), ${ }^{5}$ which is found in the majority of salivary gland secretory carcinomas, secretory breast cancers, and infantile fibrosarcomas. ${ }^{5-8}$ However, an array of different NTRK gene fusion partners have been detected, with novel fusion partners being regularly discovered. One study found 88 unique fusion partner pairs among 889 patients with TRK fusion cancer. ${ }^{9}$

\section{Technologies for the Detection of NTRK Fusions}

The development of drugs that specifically target oncogenic drivers of cancer has led to the emergence of screening technologies to identify the patients most likely to benefit from targeted treatment.

Approaches that may be used to detect NTRK gene fusions in clinical tissue samples, either indirectly or directly, include

\section{ABSTRACT}

The tropomyosin receptor kinase (TRK) family of proteins is encoded by neurotrophic tyrosine receptor kinase (NTRK) genes and has a role in the development and normal functioning of the nervous system. NTRK gene fusions have been identified as oncogenic drivers in a wide range of tumors in both adult and pediatric patients. There has recently been a paradigm shift in cancer treatment toward biomarker-based targeted therapies, as an increasing number of actionable targets are being identified across different tumors and/or tumor histologies. These targeted agents offer greater comparative effectiveness and safety vs historical nontargeted standard therapies. The development of drugs that specifically target oncogenic drivers of cancer has led to the emergence of screening technologies to identify the patients most likely to benefit from targeted therapy. This review describes the role of NTRK gene fusions in cancer and outlines the epidemiology of NTRK gene fusions, the therapeutic benefits of targeting TRK fusions with small molecule inhibitors, and recommendations for NTRK gene fusion testing in adult and pediatric patients with cancer, in order to guide treatment decisions.

Am J Manag Care. 2022;28:S15-S25

For author information and disclosures, see end of text. 
FIGURE 1. ETV6 and NTRK3 Gene Fusion Resulting in a Constitutively Active TRK Fusion Protein ${ }^{5}$

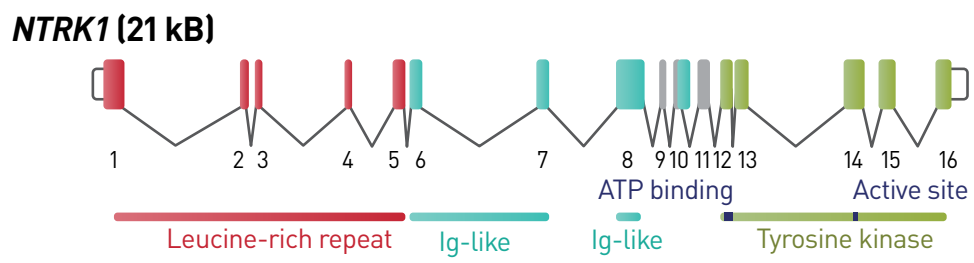

\section{NTRK2 (358 kB)}

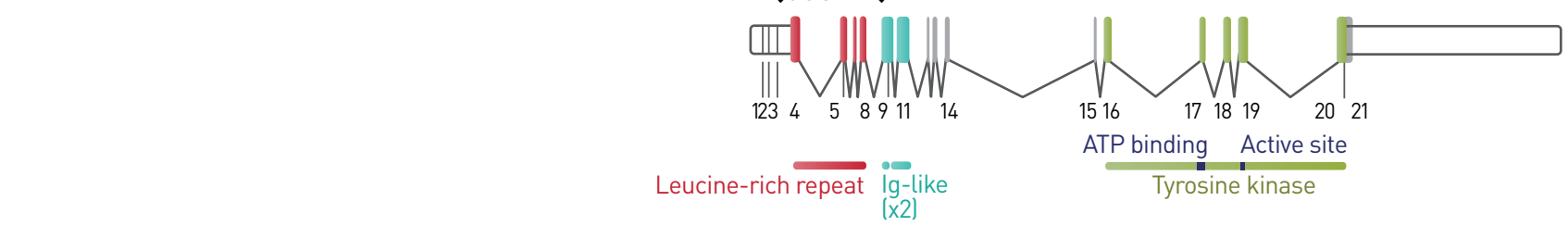

ETV6

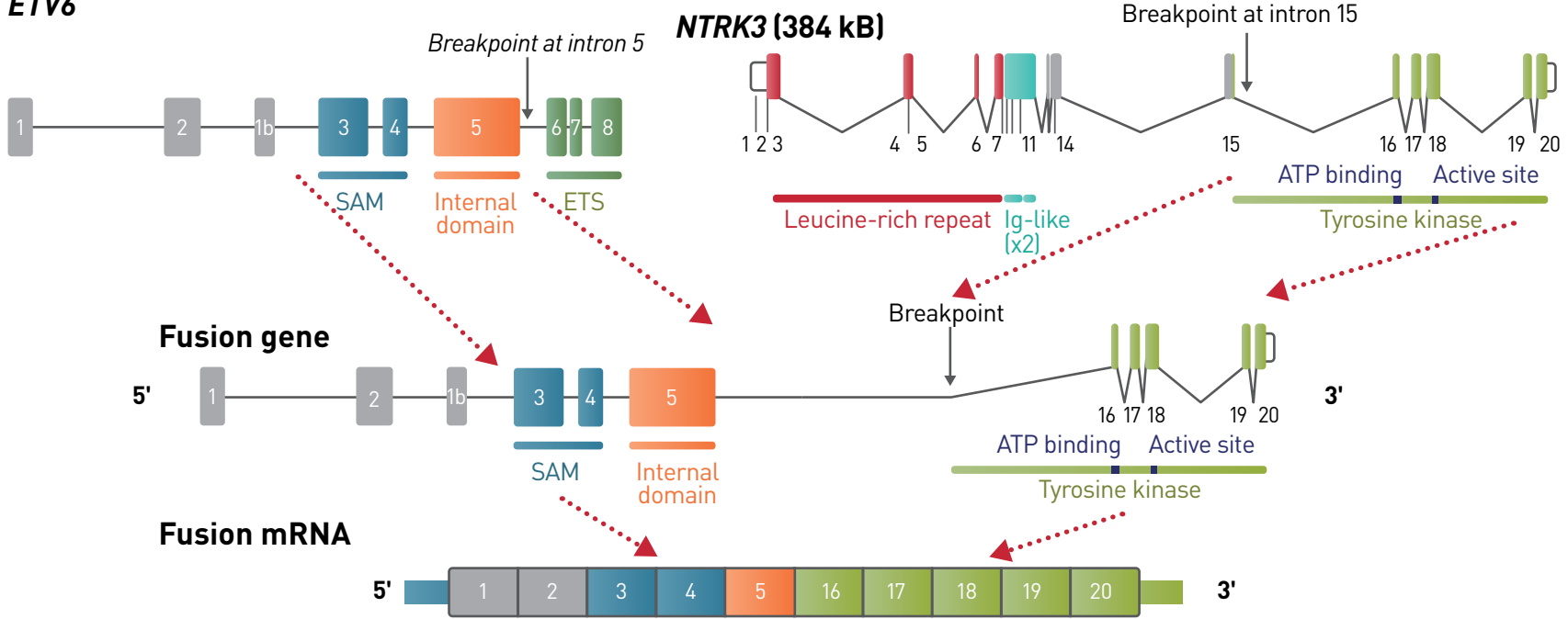

Fusion protein
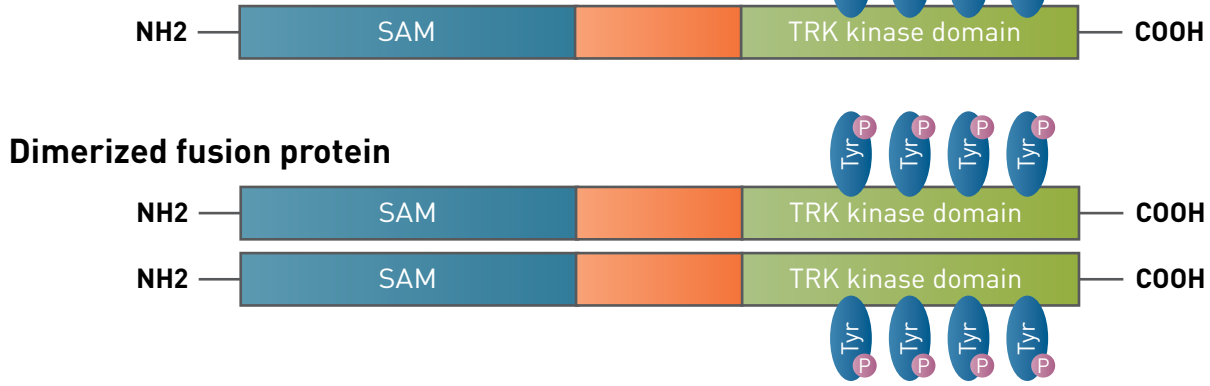

ATP, adenosine triphosphate; Ig, immunoglobulin; NTRK, neurotrophic tyrosine receptor kinase; SAM, sterile alpha motif; TRK, tropomyosin receptor kinase. Figure reproduced with permission from Penault-Llorca F et al. J Clin Pathol. 2019;72(7):460-467.

immunohistochemistry (IHC), fluorescence in situ hybridization (FISH), reverse transcriptase polymerase chain reaction (RT-PCR), and next-generation sequencing (NGS) of DNA and/or RNA (Table 1). ${ }^{5}$ IHC may be used to detect TRK overexpression as a surrogate for the presence of an NTRK gene fusion, and it is a useful screening tool in clinical settings with limited access to NGS platforms. ${ }^{5}$ IHC has proved to be a time- and tissue-efficient technique for routine screening ${ }^{10}$ and is attractive due to the low cost and universal availability compared with other technologies; however, some studies have reported challenges in the interpretation 
of IHC data. ${ }^{11}$ In particular, the specificity of IHC in central nervous system tumors can be limited due to high background TRK expression in neural tissues. ${ }^{12}$ As such, internal controls (eg, endothelial cells) and confirmatory testing using a molecular method are often recommended. ${ }^{5}$ FISH and RT-PCR, often used for testing tumor types with a high prevalence of NTRK gene fusions, are quick and costefficient but are able to detect only known, specific fusions. ${ }^{5,11}$ For FISH, a separate breakapart probe is required for each of the 3 NTRK genes, and the 5 ' gene fusion cannot be identified using this method; furthermore, FISH does not confirm whether the fusion gene is transcribed. ${ }^{11}$ RT-PCR can be an alternative or complementary approach to FISH, detecting NTRK gene fusions using primers in the coding sequence of the 5 ' fusion partner and the NTRK kinase domain. However, the large number of potential 5' fusion partners may make a comprehensive multiplex RT-PCR assay challenging. ${ }^{11,13}$ Although DNA-based NGS allows for many genomic events to be interrogated, a disadvantage is that when gene translocations are detected, it is difficult to determine if these result in functionally expressed fusions. DNA-based NGS is also less accurate in detecting gene fusions that involve large intronic regions. ${ }^{11}$ RNA-based NGS is the preferred approach due to the diverse array of reported gene fusion partners in cancer. In addition to having the ability to detect multiple genomic alterations in a single assay, RNA-based NGS is a precise, specific, and highly sensitive testing modality. ${ }^{11,13}$ However, it can be limited by RNA quality. Moreover, NGS generally is not always accessible in a clinical setting and may require relatively long turnaround times.

Based on current technology, an optimal approach to use at initial diagnosis may be tissue DNA-based NGS, complemented with RNA-based NGS. For tumors such as salivary gland secretory carcinomas and infantile fibrosarcomas that have a high prevalence of NTRK gene fusions, more specific and limited techniques that have already been described may also be appropriate.

\section{Epidemiology of NTRK Gene Fusions}

NTRK gene fusions are oncogenic drivers of various adult and pediatric cancers. ${ }^{13,6,14,15}$ Incidence and prevalence data for NTRK gene
TABLE 1. Overview of Testing Methods for NTRK Gene Fusions ${ }^{5}$

\begin{tabular}{|c|c|c|}
\hline Assay & Advantages & Disadvantages \\
\hline $\mathrm{IHC}$ & $\begin{array}{l}\text { - Low cost } \\
\text { - Readily available } \\
\text { - Detects TRKA, B, and C } \\
\text { - Turnaround time 1-2 days }\end{array}$ & $\begin{array}{l}\text { - Not specific for NTRK gene } \\
\text { fusions as it detects both } \\
\text { wild-type and fusion proteins } \\
\text { - Possible false positives } \\
\text { - Possible false negatives for } \\
\text { fusions involving TRKC } \\
\text { - No standardization of } \\
\text { scoring algorithms }\end{array}$ \\
\hline FISH & $\begin{array}{l}\text { - The location of the target within } \\
\text { the cell is visible. } \\
\text { - Several targets can be } \\
\text { detected in } 1 \text { sample using } \\
\text { several fluorophores. } \\
\text { - Requires knowledge of only } 1 \text { of } \\
\text { the } 2 \text { fusion partners when using } \\
\text { break-apart probes } \\
\text { - NTRK gene fusions with unknown } \\
\text { partners can be detected using } \\
\text { break-apart FISH. } \\
\text { - FISH is readily available in most } \\
\text { laboratories and institutes }\end{array}$ & $\begin{array}{l}\text { - The target sequence must be } \\
\text { known for conventional FISH; } \\
\text { otherwise, } 3 \text { separate tests are } \\
\text { required for NTRK1, NTRK2, } \\
\text { and NTRK3. } \\
\text { - Complex chromosomal } \\
\text { translocations can result in } \\
\text { false-positive signals. } \\
\text { - False-negative results may be } \\
\text { higher than } 30 \% \text {. }\end{array}$ \\
\hline RT-PCR & $\begin{array}{l}\text { - High sensitivity and specificity } \\
\text { - Low cost per assay }\end{array}$ & $\begin{array}{l}\text { - Target sequences must be known } \\
\text { (ie, cannot readily detect novel } \\
\text { fusion partners). } \\
\text { - A comprehensive multiplex } \\
\text { RT-PCR assay might be } \\
\text { challenging because of the } \\
\text { potentially large number of } \\
\text { 5' fusion partners. }\end{array}$ \\
\hline
\end{tabular}

- May detect novel fusion partners (depending on the assay used)

- Can be used to evaluate multiple actionable targets simultaneously while preserving limited tissue

- Currently used for NTRK testing

- RNA-NGS is preferred over DNA- NGS because sequencing for RNA-based testing is focused on coding sequences, not introns.

- Commercially available DNA-based NGS platforms may not be capable of identifying all NTRK gene fusions, especially those involving NTRK2 and NTRK3, which have large intronic regions.

- DNA-NGS is limited by intron size.

- RNA-NGS is limited by RNA quality.

FISH, fluorescence in situ hybridization; IHC, immunohistochemistry; NGS, next-generation sequencing NTRK, neurotrophic tyrosine receptor kinase; RT-PCR, reverse transcriptase polymerase chain reaction: TRK, tropomyosin receptor kinase.

Table reproduced with permission from Penault-Llorca F et al. J Clin Pathol. 2019:72(7):460-467.

fusions have only recently become available due to the increased availability of NGS and molecular testing techniques. ${ }^{1}$ Overall, solid tumors with NTRK gene fusions are rare. In 2018, the overall global incidence was estimated to be 0.52 per 100,000 persons, and the overall 5 -year prevalence was estimated to be 1.52 per 100,000 persons, based on a systematic review and meta-analysis. ${ }^{16}$ NTRK gene fusions are found at very low frequencies in more prevalent tumor types, such as lung (0.2\%; $95 \% \mathrm{CI}, 0.1 \%-0.3 \%)$ and colorectal cancer (CRC) (0.3\%; $95 \%$ CI, $0.2 \%-0.4 \%)$. However, they 
TABLE 2. Frequency of NTRK Gene Fusions in Selected Tumor Types ${ }^{16}$

\begin{tabular}{|c|c|c|}
\hline Histology & $\begin{array}{c}\text { Frequency } \\
\text { of NTRK } \\
\text { gene } \\
\text { fusions }(\%)\end{array}$ & $\begin{array}{l}95 \% \mathrm{Cl} \\
(\%-\%)\end{array}$ \\
\hline Secretory breast carcinoma & 92.9 & $72.6-100$ \\
\hline Fibrosarcoma, infantile (congenital) & 90.6 & $67.4-100$ \\
\hline Salivary gland secretory carcinoma & 79.7 & $62.8-96.5$ \\
\hline Pigmented spindle cell nevus of Reed & 56.5 & $34.5-76.8$ \\
\hline Pleomorphic adenoma & 50.5 & $0.0-100$ \\
\hline Papillary thyroid carcinoma, pediatric & 26.0 & $11.1-46.3$ \\
\hline Differentiated thyroid cancer, pediatric & 22.2 & $6.4-47.6$ \\
\hline $\begin{array}{l}\text { Congenital mesoblastic nephroma } \\
\text { (all subsets) }\end{array}$ & 21.5 & $13.1-32.2$ \\
\hline High-grade glioma & 21.2 & $9.0-38.9$ \\
\hline Low-grade mucoepidermoid carcinoma & 20.0 & $5.7-43.7$ \\
\hline Acinic cell carcinoma of salivary gland & 11.1 & $4.2-22.6$ \\
\hline $\begin{array}{l}\text { Diffuse leptomeningeal } \\
\text { glioneuronal tumor }\end{array}$ & 10.0 & $2.1-26.5$ \\
\hline \multicolumn{3}{|c|}{ Frequency of NTRK gene fusions in common tumor types } \\
\hline Cervical carcinoma & 0.4 & $0.0-0.8$ \\
\hline Uterine soft tissue sarcoma & 0.3 & $0.0-0.8$ \\
\hline Cutaneous melanoma & 0.3 & $0.1-0.6$ \\
\hline Pancreatic adenocarcinoma & 0.3 & $0.1-0.5$ \\
\hline Colorectal adenocarcinoma & 0.3 & $0.2-0.4$ \\
\hline Neuroendocrine tumors & 0.3 & $0.1-0.4$ \\
\hline Non-small cell lung cancer & 0.2 & $0.1-0.3$ \\
\hline Invasive breast carcinoma & 0.1 & $0.0-0.2$ \\
\hline \multicolumn{3}{|l|}{ Examples of primary brain tumors } \\
\hline High-grade glioma & 21.2 & $9.0-38.9$ \\
\hline $\begin{array}{l}\text { Diffuse leptomeningeal } \\
\text { glioneuronal tumor }\end{array}$ & 10.0 & $2.1-26.5$ \\
\hline High-grade glioma, pediatric & 6.2 & $3.1-9.3$ \\
\hline Glial, glioneuronal, and ependymal & 3.3 & $0.4-11.4$ \\
\hline $\begin{array}{l}\text { Dysembryoplastic neuroepithelial } \\
\text { tumors, pediatric }\end{array}$ & 3.0 & $0.1-15.8$ \\
\hline Low-grade glioma, pediatric & 1.6 & $0.0-3.3$ \\
\hline Glioma & 1.0 & $0.0-2.8$ \\
\hline Low-grade glioma & 0.9 & $0.2-1.5$ \\
\hline Glioma/neuroepithelial tumor & 0.6 & $0.2-1.1$ \\
\hline
\end{tabular}

NTRK, neurotrophic tyrosine receptor kinase.

Table reproduced with permission from Forsythe A et al. Ther Adv Med Oncol. 2020;12:1758835920975613. are common in several rare tumors, including infantile fibrosarcoma (90.6\%; 95\% CI, 67.4\%-100\%), secretory breast carcinoma (92.9\%; 95\% CI, 72.6\%-100\%), salivary gland secretory carcinoma (79.7\%; 95\% CI, 62.8\%-96.5\%), and congenital mesoblastic nephroma (21.5\%; 95\% CI, 13.1\%-32.2\%) (Table 2). ${ }^{16}$ NTRK gene fusion events appear to arise more commonly in the NTRK1 and NTRK3 genes, with the exception of primary brain tumors, in which fusions occur more commonly with NTRK2. ${ }^{1,17}$ NTRK gene fusions are also reported to occur more frequently in pediatric tumors than in adult tumors. ${ }^{18}$

\section{Real-world Evidence on TRK Fusion Cancer}

Despite significant progress in treating TRK fusion cancer, there were, until recently, limited data on the demographics, genomic characteristics, and natural history of TRK fusion cancer compared with cancers not harboring NTRK gene fusions. This has partly been due to the rarity of TRK fusion cancer and the technical limitations and variation over time of detection methods. ${ }^{19,20}$ A number of real-world studies have been conducted to investigate the co-occurrence of other biomarkers and the overall prognosis of patients with TRK fusion cancer.

\section{Co-occurrence of NTRK Gene Fusions and Other Actionable Biomarkers}

Voyager-1 was a retrospective matched cohort study; it included information on patients with solid tumors gathered from a database of deidentified electronic health records from more than 280 cancer clinics, across approximately 800 US sites. Data included clinical and demographic characteristics, treatment patterns and outcomes, and genomic data such as somatic mutations, copy number alterations, genomic rearrangements, and microsatellite instability (MSI) status. ${ }^{20}$ Voyager-2 linked genomic data from the United Kingdom's 100,000 Genomes Project with clinical data from UK cancer databases. ${ }^{21}$ Results of the 2 studies indicated that co-occurrence of oncogenic alterations in $A L K, B R A F, E R B B 2, E G F R$, $R O S 1$, and KRAS was uncommon in patients with NTRK gene fusions, supporting the hypothesis that NTRK gene fusions are the primary oncogenic drivers in tumors that harbor them, thus highlighting the importance of identifying patients with TRK fusion cancer. Furthermore, results of another study using a large real-world database of comprehensive genomic profiling data have demonstrated a lack of correlation between the presence of NTRK gene fusions and other clinically actionable biomarkers, including no co-occurrence with known oncogenic drivers in breast cancer and CRC. ${ }^{9}$ Given the low likelihood of other co-occurring oncogenic alterations in patients with NTRK gene fusions, treatment with a therapy that targets TRK is likely to provide the greatest benefit while avoiding off-target adverse events (AEs). These real-world database studies also showed that both high tumor mutational burden (TMB) and high MSI were more frequent in patients with 
CRC harboring NTRK gene fusions than in those who did not. Patients with CRC who test positive for high TMB and/or high MSI could therefore be considered an enriched population for NTRK gene fusions. These data align with previous reports that NTRK gene fusions occur more frequently in MSI-high CRC than in microsatellite stable CRC. ${ }^{22}$ Rosen et al also reported that NTRK gene fusions appear to be more common in tumors lacking canonical drivers, which, they concluded, may partially explain the tumor-agnostic efficacy of TRK inhibitors. ${ }^{19}$

\section{Natural History of TRK Fusion Cancer}

Several retrospective studies, including Voyager- 1 and Voyager-2, have evaluated the prognostic impact of NTRK gene fusions. The results from these studies suggest that the prognosis of patients with and without NTRK gene fusions is similar, with some studies showing a trend (albeit not statistically significant) toward worse prognosis in patients with TRK fusion cancer. ${ }^{20,21,23-25}$ Therefore, the outcomes observed in patients with TRK fusion cancer receiving larotrectinib or entrectinib in clinical trials (discussed later) can be considered a direct result of TRK inhibition and not due to the patients' inherent prognosis.

\section{Treatment Options for TRK Fusion Cancer}

Cancer treatment has historically been based on tumor histology and the tissue of origin. ${ }^{26}$ However, the introduction of precision oncology therapies has led to a paradigm shift, with drug development programs migrating away from histology-specific patient selection to biomarker-driven, tumor-agnostic enrichment, with a number of targeted therapies receiving tumor-agnostic regulatory approvals (eg, pembrolizumab in tumors of any type with high MSI) ${ }^{26,27}$ Larotrectinib and entrectinib are first-generation TRK inhibitors, approved for the treatment of TRK fusion cancer regardless of tumor type (Table 3)..$^{28,29}$ Several next-generation TRK inhibitors are already in clinical development.
TABLE 3. Larotrectinib and Entrectinib Label Overview 28,29,a

\begin{tabular}{|c|c|c|}
\hline Attributes & Larotrectinib & Entrectinib \\
\hline Indication & Adults and children & $\begin{array}{l}\text { Adults and children } \\
12 \text { years and older }\end{array}$ \\
\hline Dosing & $\begin{array}{l}100 \mathrm{mg} \text { twice a day } \\
\text { for adults; } \\
100 \mathrm{mg} / \mathrm{m}^{2} \text { twice } \\
\text { a day (to a maximum } \\
\text { of } 100 \mathrm{mg} \text { per dose) } \\
\text { for children }\end{array}$ & $\begin{array}{l}600 \mathrm{mg} \text { once a day for adults; } \\
300 \mathrm{mg} / \mathrm{m}^{2} \text { once a day } \\
\text { for children }\end{array}$ \\
\hline
\end{tabular}

\begin{tabular}{|ccc|}
\hline Formulation & Capsules and liquid & Capsules \\
Response rate & & \\
\hline ORR & $75 \%$ & $57 \%$ \\
\hline CR & $22 \%$ & $7.4 \%$ \\
\hline PR & $53 \%$ & $50 \%$ \\
\hline
\end{tabular}

\begin{tabular}{|c|c|c|}
\hline \multicolumn{3}{|l|}{$\begin{array}{l}\text { All-grade AEs in } \geq 20 \% \text { of } \\
\text { patients for either drug }\end{array}$} \\
\hline Fatigue & $37 \%$ & $48 \%$ \\
\hline Dizziness & $28 \%$ & $38 \%$ \\
\hline Nausea & $29 \%$ & $34 \%$ \\
\hline Dyspnea & $18 \%$ & $30 \%$ \\
\hline Myalgia & $14 \%$ & $28 \%$ \\
\hline Increased weight & $15 \%$ & $25 \%$ \\
\hline Arthralgia & $14 \%$ & $21 \%$ \\
\hline Vision disorders & NR & $21 \%$ \\
\hline Cough & $26 \%$ & $24 \%$ \\
\hline Vomiting & $26 \%$ & $24 \%$ \\
\hline Constipation & $23 \%$ & $46 \%$ \\
\hline Diarrhea & $22 \%$ & $35 \%$ \\
\hline Dysgeusia & NR & $44 \%$ \\
\hline Edema & $15 \%$ & $40 \%$ \\
\hline Dysesthesia & NR & $34 \%$ \\
\hline Cognitive impairment & NR & $27 \%$ \\
\hline Pyrexia & $18 \%$ & $21 \%$ \\
\hline
\end{tabular}

\begin{tabular}{|c|c|c|}
\hline Warnings & $\begin{array}{l}\text { Hepatotoxicity, } \\
\text { embryo-fetal toxicity, } \\
\text { neurotoxicity }\end{array}$ & $\begin{array}{l}\text { Hepatotoxicity, embryo-fetal } \\
\text { toxicity, CNS effects, congestive } \\
\text { heart failure, skeletal fractures, } \\
\text { hyperuricemia, QT interval } \\
\text { prolongation, vision disorders }\end{array}$ \\
\hline AE-related fatalities & None & $\begin{array}{l}\text { Dyspnea }(0.6 \%) \text {, pneumonia } \\
(0.6 \%) \text {, sepsis }(0.6 \%) \text {, } \\
\text { completed suicide }(0.3 \%) \text {, large } \\
\text { intestine perforation }(0.3 \%), \\
\text { tumor lysis syndrome }(0.3 \%)\end{array}$ \\
\hline
\end{tabular}

$A E$, adverse event; CNS, central nervous system; CR, complete response; NR, not reported;

ORR, objective response rate; PR, partial response.

a For illustrative purposes only; cross-trial comparisons must not be made. 
FIGURE 2. Maximum Change in Target Lesions in Response to (A) Larotrectinib and (B) Entrectinib in Patients With TRK Fusion Cancer ${ }^{35,41}$

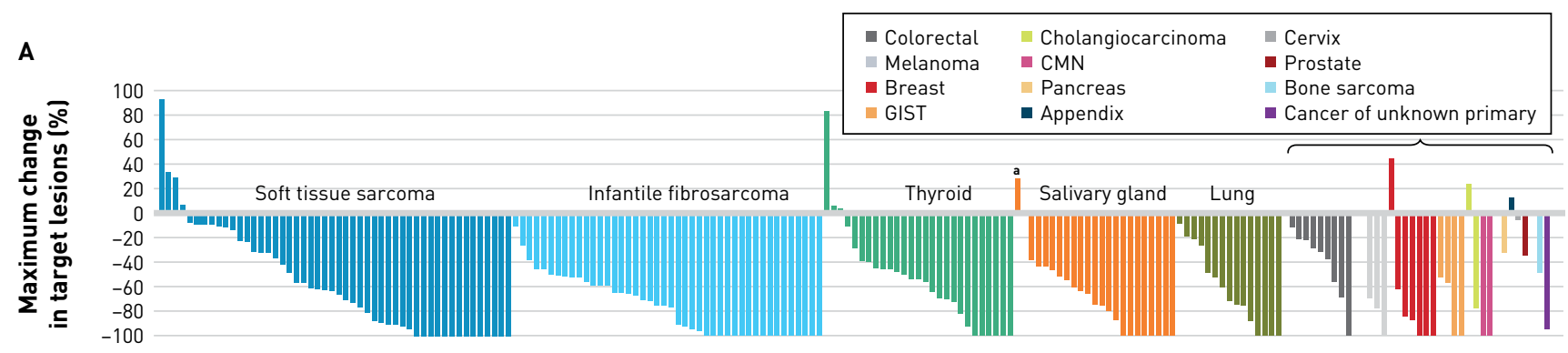

B

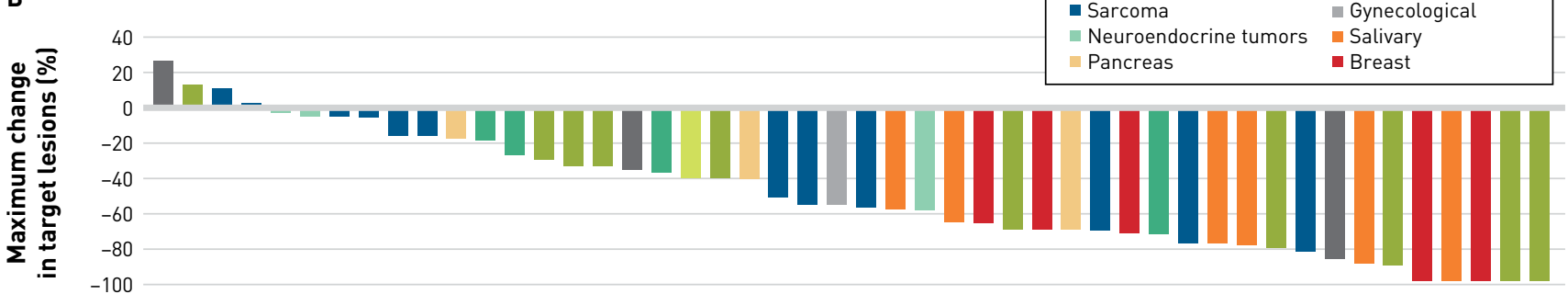

CMN, congenital mesoblastic nephroma; GIST, gastrointestinal stromal tumor; NSCLC, non-small cell lung cancer; TRK, tropomyosin receptor kinase. aThis patient had a TRK solvent front resistance mutation at baseline owing to previous therapy.

Figures reprinted with permission. (A) ๑ 2021 American Society of Clinical Oncology. All Rights Reserved. Hong DS et al. ASCO annual meeting 2021, poster 3108. (B) Doebele RC et al. Lancet Oncol. 2020;21(2):271-282.

\section{Overview of Larotrectinib}

Larotrectinib is approved in more than 40 countries, including the United States, for adult and pediatric patients of all ages with TRK fusion cancer; it is available in both capsule and liquid formulations. ${ }^{3,28,30-32}$ It is a highly selective and potent inhibitor of TRKA $\left(\mathrm{IC}_{50} 6.5 \mathrm{nM}\right)$, TRKB ( $\left.\mathrm{IC}_{50} 8.1 \mathrm{nM}\right)$, and TRKC ( $\left.\mathrm{IC}_{50} 10.6 \mathrm{nM}\right)$, with high binding affinity to all 3 receptors (more than 100 -fold higher selectivity against a panel of other kinases). ${ }^{33}$ It also inhibits the growth of cells and xenografts harboring NTRK gene fusions. ${ }^{26}$

The larotrectinib clinical development program is unique, as it encompassed patients across the age spectrum, including children aged as young as 1 month, and with a wide range of tumor types. The efficacy and safety of larotrectinib was evaluated in 3 phase $1 / 2$ clinical studies in adults and children with TRK fusion cancer, who received doses of $100 \mathrm{mg}$ (adults) or $100 \mathrm{mg} / \mathrm{m}^{2}$ (children) twice daily; these were an adult phase 1 study (NCT02122913) and the SCOUT (NCT02637687) and NAVIGATE (NCT02576431) trials. ${ }^{30,34}$ The objective response rate (ORR) from a pooled analysis of these 3 studies $(\mathrm{N}=55)$ was $75 \%$ (95\% CI, 61\%-85\%) per independent review and $80 \%$ (95\% CI, 67\%-90\%) per investigator assessment, with responses seen regardless of age, tumor type, specific NTRK gene, or fusion partner. At 1 year, $71 \%$ of the responses were ongoing and $55 \%$ of patients were progression free. The majority of AEs were grade $1 / 2$, and there were no treatment discontinuations due to AEs. ${ }^{30}$ In an expanded data set of 218 patients with TRK fusion cancer, the investigator-assessed ORR was 75\% (95\% CI, 68\%-81\%)(Table 3), ${ }^{28,29}$ and median duration of response (DOR) was 49.3 months (95\% CI, 27.3 to not estimable [NE]). ${ }^{35}$ Median progression-free survival (PFS) was 35.4 months (95\% CI, 23.4-55.7), and median overall survival (OS) was not reached..$^{35}$ Responses were seen with larotrectinib across the spectrum of tumor types included in the study (Figure 2A). ${ }^{35}$ The clinical benefits of larotrectinib are illustrated in Figure $3^{36}$ and Figure 4. Treatment-related AEs (TRAEs) observed in larotrectinib clinical trials were predominantly of grade $1 / 2$; grade $3 / 4$ TRAEs were reported in $18 \%$ of patients, the most common of which were decreased neutrophil count (7\%), increased alanine aminotransferase (3\%), and increased aspartate aminotransferase (2\%).

Patients across the age spectrum-from infants to the elderly-who received larotrectinib experienced rapid, sustained, and clinically meaningful improvements in quality of life (QOL); these improvements began within 2 months in more than two-thirds of patients. ${ }^{36,37}$ QOL scores for most patients were either maintained within or moved into the normal healthy range during larotrectinib treatment. ${ }^{36}$ Among patients with TRK fusion cancer who had 
FIGURE 3. Response to Larotrectinib in a Patient With Metastatic SQSTM1-NTRK1 Non-Small Cell Lung Cancer ${ }^{36}$
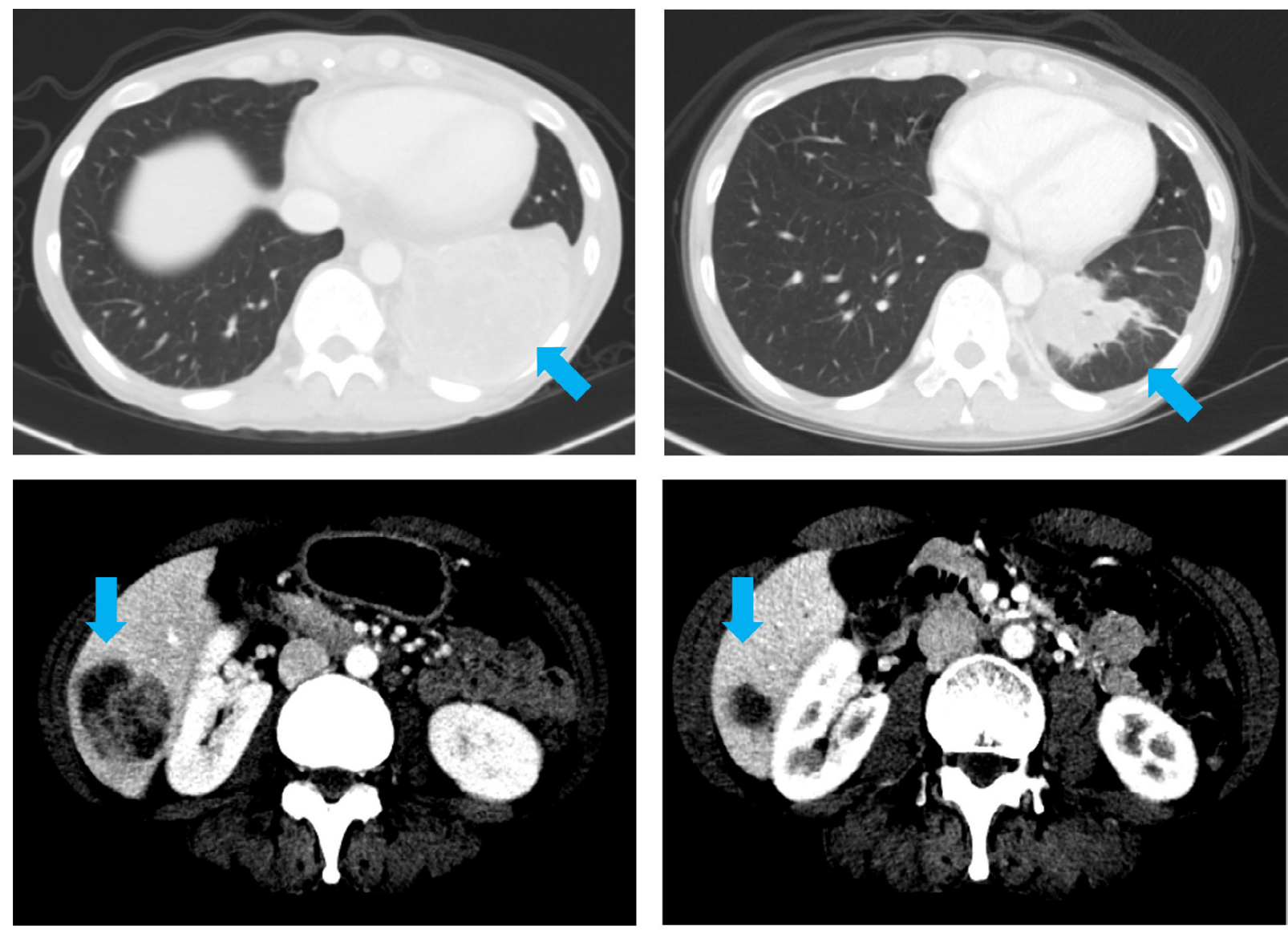

Baseline

Cycle 4

A woman, aged 45 years, had SQSTM1-NTRK1 non-small cell lung cancer with lung, liver, and mediastinal metastases. She had progressed following chemotherapy and developed pulmonary hypertrophic osteoarthropathy. She commenced larotrectinib 100 mg twice daily; within 1 week, she had joint pain relief and increased energy, and she had a partial response by cycle 4, with resolution of paraneoplastic symptoms. These clinical improvements corresponded to rapid and sustained improvements in patient-reported quality of life. After 15 months of treatment, the patient withdrew from the clinical trial following significant noncompliance. Images courtesy of Shivaani Kummar, MD, FACP. Reproduced with permission from Kummar S et al. Curr Probl Cancer. 2021;45(6):100734.

QOL below normal at baseline and were treated with larotrectinib, $91 \%$ of adults and $67 \%$ of children 2 years or older moved into the normal/above-normal QOL range following treatment. ${ }^{37}$ Sustained QOL improvements occurred within 2 months in $69 \%$ of adults and $75 \%$ of children 2 years or older and were maintained for a median duration of 12.0 months (range, 1.7-20.3) and NE (range, 1.1-23.0), respectively. With improving survival rates and increasing longterm treatment, patient-reported QOL is a particularly relevant goal to strive for, allowing patients to live both longer and better.

\section{Overview of Entrectinib}

Entrectinib, a multikinase inhibitor that targets TRK, ALK, ROS1, and JAK, is approved in the United States and the European Union for adult and pediatric patients 12 years or older with locally advanced or metastatic TRK fusion cancer; it is available in a capsule formulation. ${ }^{29,38,39}$

In vitro, entrectinib inhibits TRKA ( $\left.\mathrm{IC}_{50} 2 \mathrm{nM}\right), \mathrm{TRKB}\left(\mathrm{IC}_{50} 0.57 \mathrm{nM}\right)$, and TRKC ( $\left.\mathrm{IC}_{50} 1.1 \mathrm{nM}\right)$. It induces potent antiproliferative and apoptotic effects, as well as cell cycle arrest, in various tumor cell lines driven by NTRK gene fusion. We see inactivation of downstream AKT and ERK, in addition to antitumor activity and tumor regression, in mouse tumor models harboring NTRK fusions. ${ }^{40}$

The efficacy and safety of a once-daily 600-mg dose of entrectinib was evaluated in 4 phase $1 / 2$ clinical trials that included patients with metastatic or locally advanced TRK fusion cancer: ALKA-372-001 (EudraCT 2012-000148-88), STARTRK-1 (NCT02097810), STARTRK-2 (NCT02568267), and STARTRK-NG (NCT02650401). In an initial data set of 54 patients, 31 (57\%; $95 \%$ CI, 43.2\%-70.8\%) had 
FIGURE 4. Response to Larotrectinib in a Child With ETV6-NTRK3 Infantile Fibrosarcoma
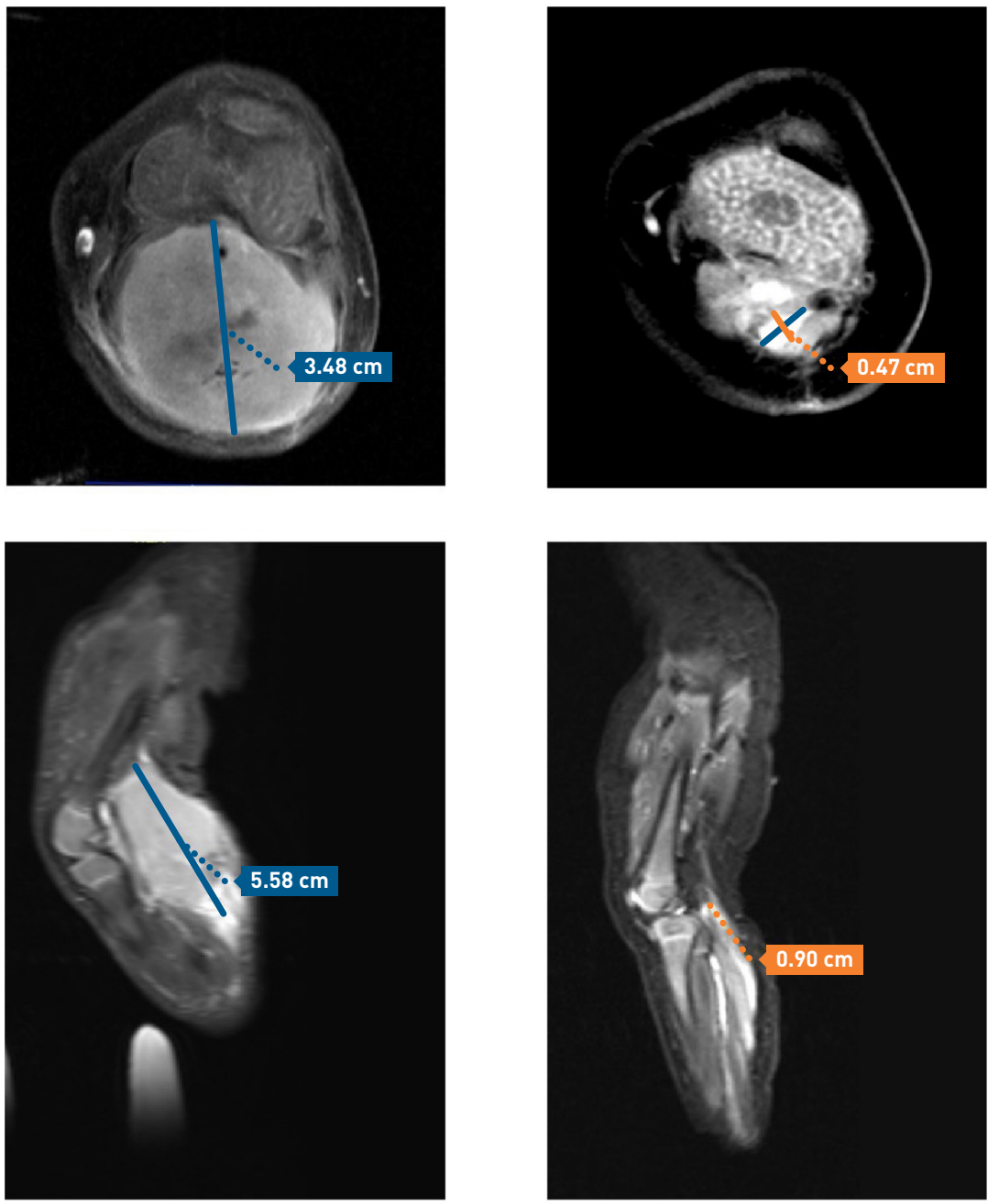

Screening MRI pretreatment

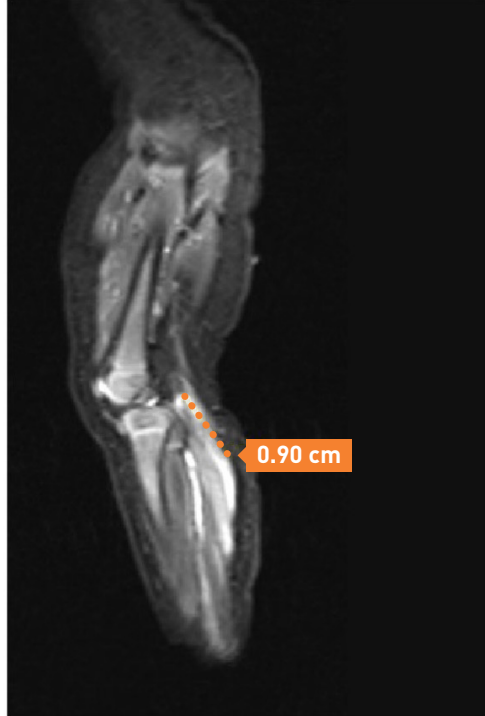
cycle 3, day 1
MRI after 2 months;

\footnotetext{
A boy, aged 1 month, had infantile fibrosarcoma in the left calf that harbored an ETV6-NTRK3 gene fusion. The tumor was treatment naive and unresectable without potential major morbidity. The patient began larotrectinib $100 \mathrm{mg} / \mathrm{m}^{2}$ twice daily and had a rapid response after 2 cycles, with $91 \%$ tumor reduction. He was able to undergo surgical resection of the residual $0.5-\mathrm{cm}$ mass when aged 8 months (cycle 6 ) and achieved a pathologic complete response. Treatment was discontinued at 2 months post resection. When aged nearly 4 years -35 months after discontinuing larotrectinib - the patient showed no evidence of disease. He was walking, running, and attending school, with normal neurocognitive development. Images courtesy of Noah Federman, MD.
}

an objective response (Table $\left.3^{28}\right) \cdot{ }^{29,41}$ Median DOR was 10 months (95\% CI, 7.1-NE), median PFS was 11 months (95\% CI, 8.0-14.9), and median OS was 21 months (95\% CI, 14.9-NE). The most common grade $3 / 4$ TRAEs were increased weight (10\%) and anemia (12\%), and the most common serious TRAEs were nervous system disorders (4\%). Treatment discontinuation due to TRAEs occurred in $4 \%$ of patients. ${ }^{41}$ In an expanded data set of 121 patients, ORR was
61\%, median DOR was 20.0 months, median PFS was 13.8 months, and median OS was 33.8 months. ${ }^{42}$

In terms of patient-reported QOL, global health status remained stable in patients with TRK fusion cancer who were treated with entrectinib during the phase 2 basket trial STARTRK-2. ${ }^{43}$ Trends toward clinical improvement were seen for role and physical functioning during treatment, and treatment- and tumor-related symptoms (eg, nausea and fatigue) remained generally stable or trended toward clinically meaningful improvement.

\section{Next-Generation TRK Inhibitors}

Acquired resistance to first-generation TRK inhibitors can arise from secondary mutations within the NTRK gene kinase domain (on-target resistance), including solvent-front substitutions and gatekeeper mutations, or activation of bypass signaling mechanisms (off-target resistance). Next-generation agents are being developed to address on-target resistance that is mediated by such emergent kinase domain mutations, while maintaining potency against wild-type TRK fusion proteins. The most advanced agents, selitrectinib and repotrectinib, are in phase $1 / 2$ development, and preliminary data suggest encouraging clinical activity. Among patients who had progressed or were intolerant to at least 1 prior TRK inhibitor, selitrectinib treatment resulted in a 34\% ORR. ${ }^{44}$ The ORR was greater (45\%) among patients with confirmed TRK kinase domain mutations. Although some data show that repotrectinib, a ROS1/TRK/ALK tyrosine kinase inhibitor, can overcome acquired resistance to prior TRK inhibition, evidence remains limited so far, generally relating only to single patients. ${ }^{45-47}$ Several other next-generation TRK inhibitors are under early investigation in patients with NTRK gene fusions; these include multikinase inhibitors (cabozantinib, merestinib, and sitravatinib) and the ROS1/TRK tyrosine kinase inhibitor taletrectinib (DS-6051b). ${ }^{48,49}$

\section{Clinical Practice Recommendations for TRK Fusion Cancer}

Integration of NTRK gene fusion testing into routine clinical practice and selection of the optimal testing modality is challenging. 
FIGURE 5. NTRK Gene Fusion Testing Algorithm ${ }^{5}$

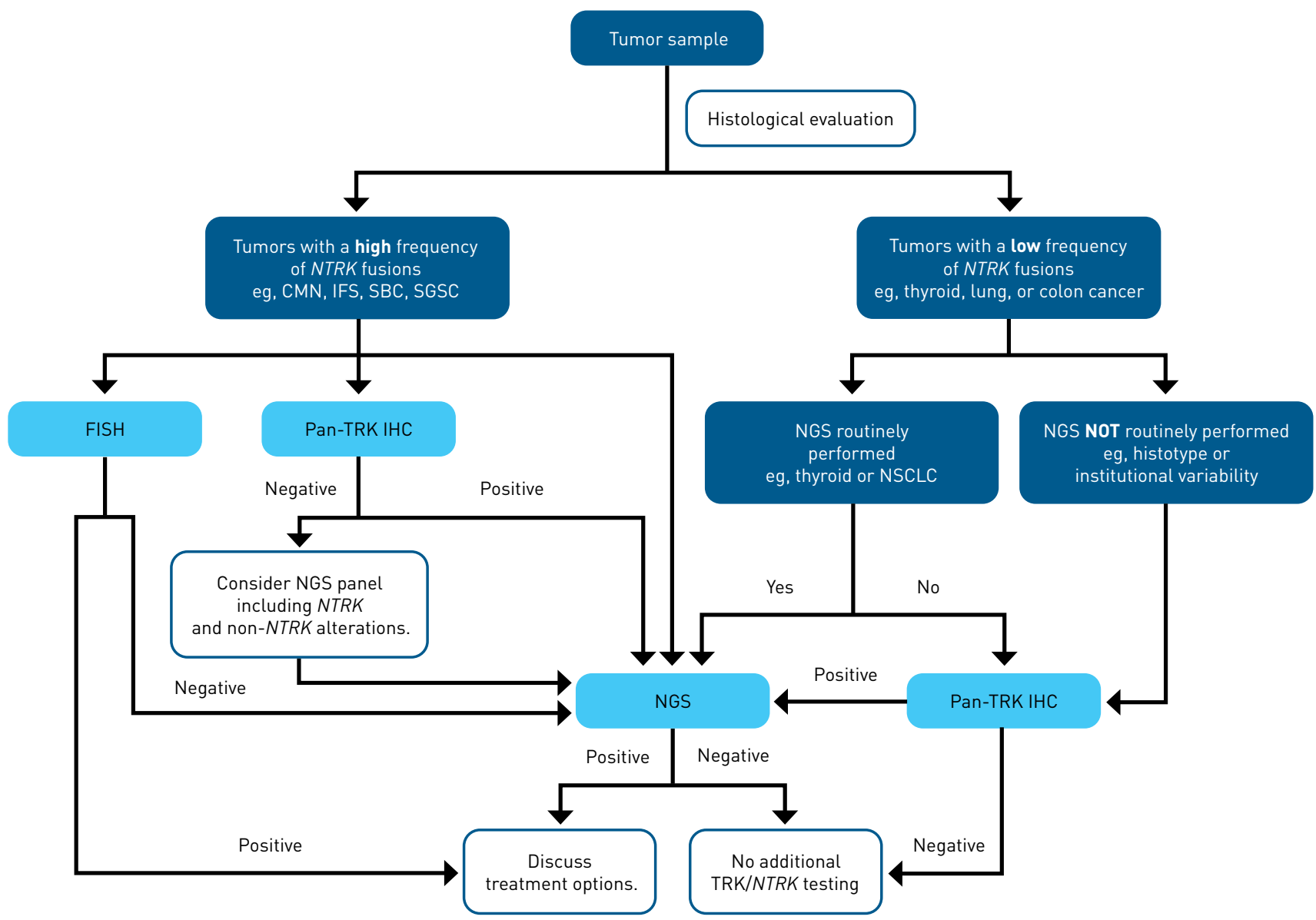

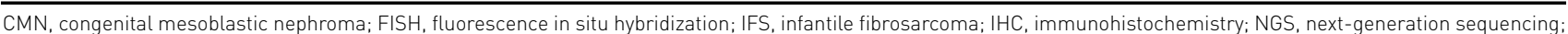
NSCLC, non-small cell lung cancer; NTRK, neurotrophic tyrosine receptor kinase; SBC, secretory breast carcinoma; SGSC, salivary gland secretory carcinoma;

TRK, tropomyosin receptor kinase.

Figure reproduced with permission from Penault-Llorca F et al. J Clin Pathol. 2019;72(7):460-467.

Several guidelines have been published that make recommendations on both the diagnosis and treatment of TRK fusion cancer.

\section{Diagnosis}

The European Society for Medical Oncology (ESMO) states that the development of optimal approaches to detect human cancers that harbor activating NTRK $1 / 2 / 3$ fusions is crucial to the administration of TRK inhibitors. In tumors in which NTRK gene fusions are highly recurrent, FISH, RT-PCR, or RNA-based NGS is recommended, whereas RNA-based NGS or IHC screening followed by sequencing is considered appropriate for testing an unselected population where fusions are uncommon..$^{50}$ ESMO guidelines also advise that the choice of assay and final diagnosis should consider the resources and clinical context. ${ }^{50}$
Penault-Llorca et al proposed a screening algorithm for identifying patients with TRK fusion cancer in clinical practice, in order to guide treatment decisions. ${ }^{5}$ The algorithm categorizes tumors based on the incidence of NTRK gene fusions, and it incorporates the strengths and availability of each testing modality (Figure 5). ${ }^{5}$ In tumors with a high frequency of NTRK gene fusions, FISH or pan-TRK IHC (if FISH is unavailable) is recommended, with confirmation by targeted NGS in patients with positive IHC. ${ }^{5}$ The pattern of TRK staining by IHC can inform the selection of confirmatory test, as tumors harboring NTRK1 rearrangements typically show strong, diffuse cytoplasmic staining. ${ }^{5}$ In contrast, tumors harboring NTRK3 rearrangements may have focal nuclear staining but weaker expression. ${ }^{5}$ Negative results from FISH or IHC should also be confirmed by NGS. In solid tumors that often harbor various gene fusions, 
but with a low frequency of NTRK gene fusions (5\%-25\%), an NGS panel that includes NTRK fusions is recommended. Lastly, for tumors with a very low frequency of NTRK gene fusions (<5\%) but in which molecular screening is common, inclusion of NTRK genes in routine NGS analysis is recommended. If NGS is not available or is not routinely utilized, pan-TRK IHC should be used for screening, followed by NGS confirmation of positive results, with RNA-based NGS being the preferred modality. Pan-TRK IHC alone is not sufficient to identify TRK fusion cancer; this is because IHC detects both wild-type and fusion TRK proteins, is associated with false-positive results, and will also detect TRK overexpression resulting from other NTRK gene alterations, such as amplification, which may not be primary oncogenic drivers.

\section{Treatment}

Larotrectinib and entrectinib are increasingly being integrated into national and international clinical practice guidelines. Clinical practice guidelines from the American Society of Clinical Oncology and ESMO recommend both agents for the treatment of progressive metastatic solid tumors with NTRK fusions, including non-small cell lung cancer, breast cancer, soft tissue sarcoma, salivary gland cancer, and thyroid cancer..$^{51-56}$

\section{Summary}

There has recently been important progress in the treatment of cancer based on tumor genomics rather than the tissue of origin. In the case of TRK fusion cancer, the inhibition of the TRK signaling pathway has been found to be an effective approach for cancer treatment in adult and pediatric patients. Although NTRK gene fusions are generally rare, they can be found in very prevalent tumors. As such, identifying patients with TRK fusion cancer allows them to potentially benefit from TRK inhibitors, which are highly effective and well tolerated. The therapeutic benefit to these patients outweighs the difficulties of identifying NTRK gene fusions. As such, NTRK gene fusion testing should be considered in patients with advanced solid tumors, regardless of tumor histology. A number of cancer clinical guidelines include recommendations for NTRK gene fusion testing, and testing algorithms have been developed for identifying patients with TRK fusion cancer in clinical practice. The long-term effects of TRK inhibition in pediatric and adolescent patients are currently unknown, but they warrant attention due to the role of TRK signaling in the development and functioning of the nervous system. Resistance to first-generation inhibitor treatment can also arise; therefore, the development of next-generation TRK inhibitors is under way. ${ }^{26}$

\section{Acknowledgments}

Medical writing support was provided by Michael Sheldon, $\mathrm{PhD}$, and editorial support was provided by George Chappell, MSc, both of Scion (London, UK), supported by Bayer according to Good Publication Practice guidelines.
Bayer was involved in fact-checking information provided in the manuscript. However, ultimate responsibility for opinions, conclusions, and data interpretation lies with the authors.

Author affiliations: Thomas Jefferson University Hospitals (MSB); University of Washington (JJC, SDS); University of California, Los Angeles (NF); Institut Bergonié (AI); Oregon Health and Science University (SK); Rigshospitalet (UL); Fred Hutchinson Cancer Research Center (SDS).

Funding source: This article was published as part of a supplement that was financially supported by Bayer HealthCare Pharmaceuticals, Inc. Noah Federman's research is supported by NIH National Center for Advancing Translational Science (NCATS) UCLA Clinical \& Translational Science Institute (CTSI) Grant Number ULITRooi88I.

Author disclosures: Dr Brose, Dr Carlson, Dr Federman, Dr Kummar, Dr Lassen, and Dr Sullivan have been part of consultancies or paid advisory boards with Bayer. Dr Brose and Dr Federman have been part of consultancies or paid advisory boards with Loxo Oncology. Dr Brose has also been part of consultancies or paid advisory boards with Genentech, AstraZeneca, and Eli Lilly and Company. Dr Brose has received honoraria from Clinical Care Options, Medscape, OncLive ${ }^{\circledR}$, and PeerView. Dr Brose has also disclosed that research support to the University of Pennsylvania School of Pharmacy has been provided by Bayer, Loxo Oncology, Genentech, Eisai, Blueprint Medicines, Eli Lilly and Company, and Novartis. Dr Carlson has received honoraria from Adaptive Biotechnologies. Dr Federman has received lecture fees for speaking at the invitation of Bayer and received patent royalties from NanoValent Pharmaceuticals, Inc. Dr Federman has also disclosed that he holds stock in the for-profit health care companies Genmab, Reata Pharmaceuticals, and bluebird bio, Inc. Dr Italiano and Dr Lassen have both received grants from Roche. Dr Italiano has also received grants from AstraZeneca, Bayer, Merck, Merck Sharp \& Dohme, and PharmaMar. Dr Italiano has disclosed that he has received honoraria from Bayer, Daiichi Sankyo, Epizyme, Ipsen, Roche, and SpringWorks Therapeutics. Dr Kummar has been part of consultancies or paid advisory boards with Boehringer Ingelheim, SpringWorks Therapeutics, Gilead, EcoRi Capital, Seagen, Mundipharma, Mirati Therapeutics, Genome \& Company, and Harbour Biomed. Dr Kummar has also disclosed that she is the cofounder and is an equity holder for PathomIQ. Dr Kummar has also disclosed that she is the editor-in-chief of Current Problems in Cancer (Elsevier) and that her spouse is a scientific adviser for Cadila Pharmaceuticals Ltd and is the founder of Arxeon Inc. Dr Lassen has also reported that he has been part of consultancies or paid advisory boards with Pfizer and Novartis. Dr Lassen has also received grants from Bristol Myers Squibb, GlaxoSmithKline, and Pfizer.

Authorship information: Analysis and interpretation of data (SK, AI, MSB, JJC, SDS, UL, NF); drafting of the manuscript (SK, AI, MSB, JJC, SDS, UL, NF); critical revision of the manuscript for important intellectual content (SK, AI, MSB, JJC, SDS, UL, NF).

Address correspondence to: Shivaani Kummar, MD, FACP; kummar@ohsu.edu

\section{REFERENCES}

1. Amatu A, Sartore-Bianchi A, Bencardino K, Pizzutilo EG, Tosi F, Siena S. Tropomyosin receptor kinase (TRK) biology and the role of NTRK gene fusions in cancer. Ann Oncol. 2019;30(suppl 8):viii5-viii15. doi:10.1093/annonc/mdz383

2. Reichardt LF. Neurotrophin-regulated signalling pathways. Philos Trans R Soc Lond B Biol Sci. 2006:361(1473):1545-1564. doi:10.1098/rstb.2006.1894

3. Cocco E, Scaltriti M, Drilon A. NTRK fusion-positive cancers and TRK inhibitor therapy. Nat Rev Clin Oncol. 2018;15(12):731-747. doi:10.1038/s41571-018-0113-0

4. Vaishnavi A, Le AT, Doebele RC. TRKing down an old oncogene in a new era of targeted therapy. Cancer Discov. 2015;5(1):25-34. doi:10.1158/2159-8290.CD-14-0765

5. Penault-Llorca F, Rudzinski ER, Sepulveda AR. Testing algorithm for identification of patients with TRK fusion cancer. J Clin Pathol. 2019;72(7):460-467. doi:10.1136/jclinpath-2018-205679

6. Skálová A, Vanecek T, Sima R, et al. Mammary analogue secretory carcinoma of salivary glands, containing the ETV6-NTRK3 fusion gene: a hitherto undescribed salivary gland tumor entity. Am J Surg Pathol. 2010;34(5):599-608. doi:10.1097/PAS.0b013e3181d9efc

7. Tognon C, Knezevich SR, Huntsman D, et al. Expression of the ETV6-NTRK3 gene fusion as a primary event in human secretory breast carcinoma. Cancer Cell. 2002;2(5):367-376. doi:10.1016/s15356108(02)00180-0

8. Bourgeois JM, Knezevich SR, Mathers JA, Sorensen PH. Molecular detection of the ETV6-NTRK3 gene fusion differentiates congenital fibrosarcoma from other childhood spindle cell tumors. Am J Surg Pathol. 2000;24(7):937-946. doi:10.1097/00000478-200007000-00005

9. Westphalen CB, Krebs MG, Le Tourneau C, et al. Genomic context of NTRK1/2/3 fusion-positive tumours from a large real-world population. NPJ Precis Oncol. 2021;5(1):69. doi:10.1038/s41698-021-00206-y 
10. Hechtman JF, Benayed R, Hyman DM, et al. Pan-Trk immunohistochemistry is an efficient and reliable screen for the detection of NTRK fusions. Am J Surg Pathol. 2017:41(11):1547-1551. doi10.1097/ PAS.0000000000000911

11. Solomon JP, Benayed R, Hechtman JF, Ladanyi M. Identifying patients with NTRK fusion cancer. Ann Oncol. 2019;30(suppl 8):viiii16-viii22. doi:10.1093/annonc/mdz384

12. Gambella A, Senetta R, Collemi G, et al. NTRK fusions in central nervous system tumors: a rare, but worthy target. Int J Mol Sci. 2020;21(3):753. doi:10.3390/ijms21030753

13. Beadling C, Wald Al, Warrick A, et al. A multiplexed amplicon approach for detecting gene fusions by next-generation sequencing. J Mol Diagn. 2016;18(2):165-175. doi:10.1016/j.jmoldx.2015.10.002

14. Shukla N, Roberts SS, Baki MO, et al. Successful targeted therapy of refractory pediatric ETV6-NTRK3 fusion-positive secretory breast carcinoma. JCO Precis Oncol. 2017;2017:P0.17.00034. doi:10.1200/P0.17.00034

15. Nagasubramanian R, Wei J, Gordon P, Rastatter JC, Cox MC, Pappo A. Infantile fibrosarcoma with NTRK3-ETV6 fusion successfully treated with the tropomyosin-related kinase inhibitor LOXO-101. Pediatr Blood Cancer. 2016;63(8):1468-1470. doi:10.1002/pbc.26026

16. Forsythe A, Zhang W, Strauss UP, Fellous M, Korei M, Keating K. A systematic review and metaanalysis of neurotrophic tyrosine receptor kinase gene fusion frequencies in solid tumors. Ther Adv Med Oncol. 2020;12:1758835920975613. doi:10.1177/1758835920975613

17. Kummar S, Lassen UN. TRK inhibition: a new tumor-agnostic treatment strategy. Targeted Oncol. 2018;13(5):545-556. doi:10.1007/s11523-018-0590-1

18. Zhao X, Kotch C, Fox E, et al. NTRK fusions identified in pediatric tumors: the frequency, fusion partners, and clinical outcome. JCO Precis Oncol. 2021;1:P0.20.00250. doi:10.1200/P0.20.00250 19. Rosen EY, Goldman DA, Hechtman JF, et al. TRK fusions are enriched in cancers with uncommon histologies and the absence of canonical driver mutations. Clin Cancer Res. 2020;26(7):1624-1632. doi:10.1158/1078-0432.CCR-19-3165

20. Bazhenova L, Lokker A, Snider J, et al. TRK fusion cancer: patient characteristics and survival analy sis in the real-world setting. Targeted Oncol. 2021;16(3):389-399. doi:10.1007/s11523-021-00815-4 21. Bridgewater J, Jiao X, Parimi M, et al. Abstract 394: prognosis and molecular characteristics of patients with TRK fusion cancer in the 100,000 Genomes Project. Cancer Res. 2021;81(suppl 13). doi:10.1158/1538-7445.AM2021-394

22. Pietrantonio F, Di Nicolantonio F. Schrock AB, et al. ALK, ROS1, and NTRK rearrangements in metastatic colorectal cancer. J Natl Cancer Inst. 2017;109(12). doi:10.1093/jnci/djx089

23. Demetri GD, Peters S, Hibbar DP, et al. 100P - characteristics and outcomes of patients (pts) with NTRK fusion-positive (NTRK+) metastatic / locally advanced (LA) solid tumours receiving non-TRK inhibitor (TRKi) standard of care (SoC), and prognostic value of NTRK fusions in clinical practice. Ann Oncol. 2021:32(suppl 5):S399. doi:10.1016/annonc/annonc686

24. Zhu L, Hobbs B, Roszik J, Holla V, Hong DS. Investigating the natural history and prognostic nature of NTRK gene fusions in solid tumors. Invest New Drugs. Published online August 2, 2021. doi:10.1007/ s10637-021-01157-8

25. Santi I, Vellekoop H, Huygens S, Rutten-van Molken M, Versteegh M. 105P - prognostic value of the NTRK fusion biomarker in the Netherlands. Ann Oncol. 2021;32(suppl 5):S401-S402. doi:10.1016/j. annonc.2021.08.385

26. Drilon A. TRK inhibitors in TRK fusion-positive cancers. Ann Oncol. 2019-30(suppl 8):viii23-viii30. doi:10.1093/annonc/mdz282

27. Le DT, Uram JN, Wang H, et al. PD-1 blockade in tumors with mismatch-repair deficiency. N Engl J Med. 2015:372(26):2509-2520. doi:10.1056/NEJMoa1500596

28. Vitrakvi. Prescribing information. Bayer HealthCare Pharmaceuticals; updated March 2021. Accessed November 15, 2021. https://www.accessdata.fda.gov/drugsatfda_docs/label/2021/210861s006lbl.pdf 29. Rozlytrek. Prescribing information. Genentech; updated November 2021. Accessed November 15 2021. https://www.gene.com/download/pdf/rozlytrek_prescribing.pdf

30. Drilon A, Laetsch TW, Kummar S, et al. Efficacy of larotrectinib in TRK fusion-positive cancers in adults and children. N Engl J Med. 2018;378(8):731-739. doi:10.1056/NEJMoa1714448

31. Bayer AG. Vitrakvi: annex I - summary of product characteristics. European Medicines Agency; updated May 2021. Accessed October 1, 2021. https://www.ema.europa.eu/en/documents/product-information/ vitrakvi-epar-product-information en.pdf

32. Precision oncology treatment larotrectinib submitted for marketing authorization in China. News release. Bayer Global; May 25, 2021. Accessed October 1, 2021. https://media.bayer.com/baynews/ baynews.nst/id/20E13B140081FE60C12586DCO03CE87C?open\&ref=irrefndcd

33. Ghilardi JR, Freeman KT, Jimenez-Andrade JM, et al. Administration of a tropomyosin receptor kinase inhibitor attenuates sarcoma-induced nerve sprouting, neuroma formation and bone cancer pain. Mol Pain. 2010;6:87. doi:10.1186/1744-8069-6-87

34. Hong DS, DuBois SG, Kummar S, et al. Larotrectinib in patients with TRK fusion-positive solid tumours: a pooled analysis of three phase 1/2 clinical trials. Lancet Oncol. 2020;21(4):531-540. doi:10.1016/S1470-2045(19)30856-3
35. Hong DS, Shen L, Van Tilburg CM, et al. Long-term efficacy and safety of larotrectinib in an integrated dataset of patients with TRK fusion cancer. J Clin Oncol. 2021;39(suppl 15):abstr 3108. doi:10.1200/ JCO.2021.39.15 suppl.3108

36. Kummar S, Berlin J, Mascarenhas L, et al. Quality of life in adult and pediatric patients with tropomyosin receptor kinase fusion cancer receiving larotrectinib. Curr Probl Cancer. Published online April 2 2021. doi:10.1016/j.currproblcancer.2021.100734

37. Kummar S, Van Tilburg CM, Albert CM, et al. Quality of life of adults and children with TRK fusion cancer treated with larotrectinib compared to the general population. J Clin Oncol. 2020;38(suppl 15):abstr 3614. doi:10.1200/JC0.2020.38.15 suppl.3614

38. Menichincheri M, Ardini E, Magnaghi P, et al. Discovery of entrectinib: a new 3-aminoindazole as a potent anaplastic lymphoma kinase (ALK), c-ros oncogene 1 kinase (ROS1), and pan-tropomyosin receptor kinases (Pan-TRKs) inhibitor. J Med Chem. 2016;59(7):3392-3408. doi:10.1021/acs.jmedchem.6b00064 39. Roche Pharma AG. Rozlytrek: annex I - summary of product characteristics. European Medicines Agency; updated September 2021. Accessed October 1, 2021. https://www.ema.europa.eu/en/documents/ product-information/rozlytrek-epar-product-information en.pdf

40. Liu D, Offin M, Harnicar S, Li BT, Drilon A. Entrectinib: an orally available, selective tyrosine kinase inhibitor for the treatment of NTRK, ROS1, and ALK fusion-positive solid tumors. Ther Clin Risk Manag. 2018;14:1247-1252. doi:10.2147/TCRM.S14738

41. Doebele RC, Drilon A, Paz-Ares L, et al; trial investigators. Entrectinib in patients with advanced or metastatic NTRK fusion-positive solid tumours: integrated analysis of three phase 1-2 trials. Lancet Oncol. 2020;21(2):271-282. doi:10.1016/S1470-2045(19)30691-6

42. Bazhenova L, Liu SV, Lin JJ, et al. 533P - efficacy and safety of entrectinib in patients with locally advanced/metastatic NTRK fusion-positive (NTRK-fp) solid tumours. Ann Oncol. 2021:32(suppl 5):S598-S599. doi:10.1016/annonc/annonc699

43. Paz-Ares L, Barlesi F, Siena S, et al. Patient-reported outcomes from STARTRK-2: a global phase II basket study of entrectinib for ROS1 fusion-positive non-small-cell lung cancer and NTRK fusion-positive solid tumours. ESMO Open. 2021;6(3):100113. doi:10.1016/j.esmoop.2021.100113

44. Hyman D, Kummar S, Farago A, et al. Phase I and expanded access experience of LOXO-195 (BAY 2731954), a selective next-generation TRK inhibitor (TRKi). Cancer Res. 2019;79(suppl 13):abstr CT127. doi:10/1158/1538-7445.AM2019-CT127

45. Drilon A, Ou S-HI, Cho BC, et al. Repotrectinib (TPX-0005) is a next-generation ROS1/TRK/ALK inhibitor that potently inhibits ROS1/TRK/ALK solvent-front mutations. Cancer Discov. 2018:8(10):1227-1236. doi:10.1158/2159-8290.CD-18-0484

46. Drilon AEDC, Zhai D. Deng W, et al. Abstract 442: repotrectinib, a next generation TRK inhibitor, overcomes TRK resistance mutations including solvent front, gatekeeper and compound mutations. Presented at: American Association for Cancer Research Annual Meeting; March 29-April 3, 2019; Atlanta, GA. 47. Murray BW, Rogers E, Zhai D, et al. Molecular characteristics of repotrectinib that enable potent inhibition of TRK fusion proteins and resistant mutations. Mol Cancer Ther. Published online October 8 , 2021. doi:10.1158/1535-7163.MCT-21-0632

48. Chu P, Batson S, Hodgson M, Mitchell CR, Steenrod A. Systematic review of neurotrophic tropomyosin-related kinase inhibition as a tumor-agnostic management strategy. Future Oncol. 2020;16(4):61-74. doi:10.2217/fon-2019-0534

49. Papadopoulos KP, Borazanci E, Shaw AT, et al. U.S. phase I first-in-human study of taletrectinib (DS-6051b/AB-106), a ROS1/TRK inhibitor, in patients with advanced solid tumors. Clin Cancer Res. 2020;26(18):4785-4794. doi:10.1158/1078-0432.CCR-20-1630

50. Marchiò C. Scaltriti M, Ladanyi M, et al. ESMO recommendations on the standard methods to detect NTRK fusions in daily practice and clinical research. Ann Oncol. 2019;30(9):1417-1427. doi:10.1093/annonc/mdz204

51. Cardoso F, Paluch-Shimon S, Senkus E, et al. 5th ESO-ESMO International Consensus Guidelines for advanced breast cancer (ABC 5). Ann Oncol. 2020;31(12):1623-1649. doi:10.1016/j.annonc.2020.09.010 52. Filetti S, Durante C, Hartl D, et al; ESMO Guidelines Committee. Thyroid cancer: ESMO Clinical Practice Guidelines for diagnosis, treatment and follow-up. Ann Oncol. 2019;30(12):1856-1883. doi:10.1093/annonc/mdz400

53. Planchard D, Popat S, Kerr K, et al; ESMO Guidelines Committee. Metastatic non-small cell lung cancer: ESMO Clinical Practice Guidelines for diagnosis, treatment and follow-up. Ann Oncol. 2018;29(suppl 4):iv192-iv237. doi:10.1093/annonc/mdy275

54. Geiger JL, Ismaila N, Beadle B, et al. Management of salivary gland malignancy: ASCO Guideline. J Clin Oncol. 2021;39(17):1909-1941. doi:10.1200/JC0.21.00449

55. Hanna NH, Robinson AG, Temin S, et al. Therapy for stage IV non-small-cell lung cancer with driver alterations: ASCO and OH (CCO) Joint Guideline update. J Clin Oncol. 2021;39(9):1040-1091. doi:10.1200/ JCO.20.03570

56. Gronchi A, Miah AB, Dei Tos AP, et al; ESMO Guidelines Committee, EURACAN and GENTURIS. Soft tissue and visceral sarcomas: ESMO-EURACAN-GENTURIS Clinical Practice Guidelines for diagnosis, treatment and follow-up. Ann Oncol. 2021;32(11):1348-1365. doi:10.1016/j.annonc.2021.07.006 


\title{
Comparative Effectiveness of Larotrectinib and Entrectinib for TRK Fusion Cancer
}

\author{
Josh J. Carlson, PhD, MPH; Antoine Italiano, MD, PhD; Marcia S. Brose, MD, PhD; \\ Noah Federman, MD; Ulrik Lassen, MD, PhD; Shivaani Kummar, MD, FACP; \\ Sean D. Sullivan, PhD, MSc, RPh
}

\section{Introduction}

Larotrectinib and entrectinib are tumor-agnostic treatments for advanced or metastatic solid tumors harboring neurotrophic tyrosine receptor kinase (NTRK) gene fusions. NTRK gene fusions are oncogenic drivers in a diverse range of tumor types, including lung cancer, colorectal cancer, thyroid cancer, salivary gland cancer, and sarcomas. These gene alterations are present in tumors of both adults and children. ${ }^{1}$ Although NTRK gene fusions are generally rare, occurring in less than $1 \%$ of all cancers overall, ${ }^{1,2}$ they are highly prevalent in certain rare tumors (eg, secretory breast carcinoma, secretory carcinoma of the salivary gland, infantile fibrosarcoma, and congenital mesoblastic nephroma). ${ }^{3}$ The rarity of NTRK gene fusions, combined with the diverse range of tumor types in which they are found and the heterogeneity of tumor-specific standard-of-care treatments, makes the clinical evaluation of tropomyosin receptor kinase (TRK) inhibitors challenging and the use of gold-standard randomized controlled trials unfeasible. ${ }^{4-6}$

Drug development programs have adapted to integrate biomarker-driven tumor-agnostic approaches into trial design. Indeed, the TRK inhibitors larotrectinib and entrectinib were among the earliest cancer drugs to receive tumor-agnostic approvals from the US FDA and European Medicines Agency (EMA). Both are approved for use in locally advanced or metastatic TRK fusion cancer that has progressed with standard-of-care therapies and in which no alternative satisfactory treatment options exist or where surgical resection is likely to result in severe morbidity. Larotrectinib is approved for adults and pediatric patients 1 month or older. Entrectinib is approved for adults and pediatric patients 12 years or older. ${ }^{7-10}$

Regulatory approvals for both larotrectinib and entrectinib were based on findings from single-arm phase $1 / 2$ studies, including basket trials that enrolled patients based on the presence of NTRK gene fusions, regardless of age or tumor type. ${ }^{11-13}$ Despite regulatory acceptance of this adaptive trial approach, there remains a paucity of comparative effectiveness data for TRK inhibitors vs established standard-of-care treatments, which presents a challenge to their integration into routine clinical practice. In addition, no studies have directly compared the effects of larotrectinib and entrectinib in TRK fusion cancer.

\section{ABSTRACT}

Larotrectinib and entrectinib are tumor-agnostic tropomyosin receptor kinase (TRK) inhibitors that are indicated for the treatment of advanced or metastatic solid tumor cancers with neurotrophic tyrosine receptor kinase (NTRK) gene fusions. Regulatory approval of both agents was based on data from single-arm phase $1 / 2$ studies, including tumor-agnostic basket trials. In the absence of randomized controlled trials, there remains a paucity of data to demonstrate the comparative effectiveness of larotrectinib and entrectinib vs established standard-of-care treatments in cancers with NTRK gene fusions. Furthermore, no studies have directly compared the 2 agents. This article reviews what is known about the comparative effectiveness of larotrectinib and entrectinib vs standard therapies in TRK fusion cancer and examines the comparative effectiveness of the 2 TRK inhibitors. Historical and intrapatient comparisons suggest that TRK inhibitors improve disease response compared with preexisting treatments across most tumor histologies; indirect and limited comparisons of phase 1/2 data and preliminary simulation modeling suggest a potential advantage for larotrectinib over entrectinib in terms of clinical response and survival. Although limited, these data provide some insight into the position of these treatments in established treatment paradigms for TRK fusion cancer, a setting where real-world evidence will be slow to accrue due to the rare nature of these tumors but may be the only way in the future to answer the outstanding questions regarding these 2 agents. Meanwhile, we need to try to obtain the maximum benefit that can be achieved for our patients using the currently available knowledge. 
The American Society of Clinical Oncology and European Society for Medical Oncology clinical practice guidelines recommend either larotrectinib or entrectinib as treatment options for solid tumors with NTRK gene fusions, including breast, non-small cell lung cancer (NSCLC), soft tissue sarcoma, salivary, and thyroid ${ }^{14-19}$; however, these guidelines provide no indication of the relative effectiveness of the 2 agents. Furthermore, switching from one TRK inhibitor to another has not been investigated and is not recommended due to the likely development of mechanisms of cross-resistance, which can include the appearance of resistance mutations in these genes. ${ }^{12,20,21}$ Thus, the initial decision between the 2 drugs represents the only opportunity to choose the most appropriate first-generation TRK inhibitor for each individual patient.

In this article, we review the comparative effectiveness of larotrectinib, entrectinib, and non-TRK-targeted standard-of-care therapies for TRK fusion cancer, utilizing indirect comparisons that aimed to overcome the challenge of translating tumor-agnostic basket trial data into clinical practice.

\section{Efficacy of TRK Inhibitors vs Standard-of-Care Therapies}

The initial FDA approval of larotrectinib for TRK fusion cancer was based on a pooled analysis of patients from 3 phase $1 / 2$ trials (including a basket trial) in adult, adolescent, and pediatric patients: an adult phase 1 study (NCT02122913); the phase 1/2 SCOUT study (NCT02637687); and the phase 2 NAVIGATE basket study (NCT02576431). In the first publication of data from these trials (in 55 patients with 17 different tumors), the investigator-assessed objective response rate (ORR) was $80 \% .{ }^{12}$ In a more recent analysis carried out in an expanded population of 218 patients, the ORR was $75 \%$, with a median duration of response (DOR) of 49.3 months and a median progression-free survival (PFS) of 35.4 months. Responses were seen regardless of tumor type. Median overall survival (OS) had not been reached after a median follow-up of 22.3 months. The 36-month OS rate was $77 \% .^{22}$

The regulatory data set for the US approval of entrectinib was based on a pooled analysis of 54 adult patients with solid tumors and NTRK gene fusions from 3 single-arm phase $1 / 2$ trials: ALKA-372-001 (EudraCT 2012-000148-88), STARTRK-1 (NCT02097810), and STARTRK-2 (NCT02568267). ${ }^{11}$ The European approval was based on an expanded data set of 74 patients. ${ }^{10}$ Entrectinib was associated with these responses: ORR, 57\%; median DOR, 10.4 months; median PFS, 11.2 months; and median OS, 21 months. ${ }^{11}$ The STARTRK-NG trial subsequently provided evidence of tumor response and durable disease control with entrectinib in adolescent and pediatric patients. ${ }^{13,23}$ The clinical data for larotrectinib and entrectinib are reviewed in more detail by Kummar et al in this supplement.

Although basket trials offer an adaptive tumor-agnostic solution and were requested for regulatory purposes to provide evidence of efficacy and safety of both larotrectinib and entrectinib, some questions remain regarding the translation of these findings to clinical practice. The very nature of the basket trial adds patient-level histological heterogeneity, with many individual and rare tumor types grouped together due to their common oncogenic driver. Widely different prognoses across cancers of different origins, along with the absence of a single standard-of-care treatment across distinct tumor histologies, confound interpretation and extrapolation of time-to-event outcomes (eg, survival) from these studies to the clinic. ${ }^{6}$ Nevertheless, it is crucial that clinicians and decision makers understand the place of tumor-agnostic therapies in the established treatment paradigm for specific cancers. Historical data comparisons for specific tumor histologies and intrapatient comparisons are 2 methods that have been used to indirectly compare the clinical efficacy of larotrectinib, entrectinib, and standard-of-care treatment.

\section{Comparative Effectiveness vs Historical Standard Therapies}

Pollack and colleagues indirectly compared historical treatment data for advanced-stage/metastatic solid tumor histologies known to harbor NTRK gene fusions (NSCLC, colorectal cancer, thyroid cancer, gliomas, soft tissue sarcoma, salivary gland cancer, and infantile fibrosarcoma) with pooled phase $1 / 2$ data from the 3 larotrectinib trials to provide a side-by-side comparison of efficacy. ${ }^{6}$ Despite small patient numbers, the ORR for larotrectinib was higher than that reported previously for historical standard treatments across most specific tumor histologies, especially in later lines of therapy where larotrectinib is most likely to be used (Table). ${ }^{6}$ This is not surprising in that the efficacy of chemotherapy and other systemic treatments decreases with subsequent lines of therapy, as the disease becomes more resistant. ${ }^{24,25}$ In NSCLC, for instance, the observed ORR for larotrectinib was $75 \%$ compared with up to $29 \%$ for second-line or subsequent historical treatment. Similar trends were observed for colorectal cancer, soft tissue sarcomas, and salivary gland cancers. Although the findings of these comparisons are of interest, it must be noted that these were general comparisons of outcomes observed in a small number of patients from the larotrectinib trials. No matching for demographic or clinical variables was performed, and outcomes were compared with an unselected historical tumor histology-based population receiving standard therapies in which NTRK gene fusion status was unknown. However, retrospective real-world database analyses have demonstrated that NTRK gene fusion status has no prognostic impact across various tumor types in the absence of TRK-targeted therapies. ${ }^{26,27}$

\section{Intrapatient Comparison}

Growth modulation index (GMI) analyses may provide a more informative comparison of TRK inhibitor effectiveness vs standard therapy in the setting of rare TRK fusion cancer, overcoming some 
TABLE. Efficacy of Larotrectinib and Entrectinib vs Tumor Histology-Specific Treatments ${ }^{6}$

\begin{tabular}{|c|c|c|c|c|c|}
\hline \multirow[b]{2}{*}{ Tumor type } & \multicolumn{3}{|c|}{ Historical treatments } & \multicolumn{2}{|c|}{$\begin{array}{l}\text { Larotrectinit } \\
\qquad(n=159)\end{array}$} \\
\hline & Treatment line/treatment & $\mathbf{n}$ & $\begin{array}{l}\text { ORR } \\
\text { (\%) }\end{array}$ & $\mathbf{n}$ & $\begin{array}{l}\text { ORR } \\
\text { [\%] }\end{array}$ \\
\hline NSCLC & $\begin{array}{l}\geq 2 \mathrm{~L} \text { chemotherapy ( } \pm \text { VEGF } \\
\text { inhibitor) or immunotherapy }\end{array}$ & $19-628$ & $2.7-28.9$ & 12 & 75 \\
\hline \multirow{2}{*}{ Colorectal } & $\begin{array}{l}\geq 2 \text { L chemotherapy ( } \pm \text { VEGF } \\
\text { inhibitor) or VEGF inhibitor }\end{array}$ & $16-614$ & $0-47.7$ & \multirow{2}{*}{8} & \multirow{2}{*}{50} \\
\hline & $\begin{array}{l}\geq 3 \text { L chemotherapy } \\
\text { or VEGF inhibitor }\end{array}$ & $91-534$ & $1-13$ & & \\
\hline \multirow[t]{2}{*}{ Thyroid } & $\begin{array}{l}\geq 1 \mathrm{~L} \text { chemotherapy } \\
\text { or VEGF inhibitor or } \\
\text { chemotherapy }+\mathrm{XRT} \pm \text { surgery }\end{array}$ & $9-207$ & $0-64.8$ & \multirow[t]{2}{*}{24} & \multirow[t]{2}{*}{79} \\
\hline & $\begin{array}{l}\geq 2 \mathrm{~L} \text { chemotherapy or VEGF } \\
\text { inhibitor }\end{array}$ & $20-34$ & 0 & & \\
\hline Glioma & $\begin{array}{l}\geq 2 \mathrm{~L} \text { chemotherapy or VEGF } \\
\text { inhibitor ( } \pm \text { chemotherapy) }\end{array}$ & $22-40$ & $63-95.2$ & 14 & 36 \\
\hline \multirow{2}{*}{ Salivary } & $1 \mathrm{~L}$ chemotherapy & 42 & 31 & \multirow{2}{*}{20} & \multirow{2}{*}{90} \\
\hline & 2L chemotherapy & 18 & 5 & & \\
\hline $\begin{array}{l}\text { Non-GIST } \\
\text { soft tissue } \\
\text { sarcoma }\end{array}$ & $\begin{array}{l}\geq 1 \mathrm{~L} \text { chemotherapy } \\
\text { or mTOR inhibitor or } \\
\text { surgery + chemotherapy+XRT }\end{array}$ & $6-175$ & $13.2-44.4$ & 36 & 81 \\
\hline $\begin{array}{l}\text { Infantile } \\
\text { fibrosarcoma }\end{array}$ & $1 \mathrm{~L}$ surgery+ chemotherapy & $6-20$ & $71-88.9$ & 28 & 96 \\
\hline
\end{tabular}

GIST, gastrointestinal stromal tumor; mTOR, mechanistic target of rapamycin;

NSCLC, non-small cell lung cancer; $1 \mathrm{~L}$, first line; ORR, objective response rate; $2 \mathrm{~L}$, second line;

$3 \mathrm{~L}$, third line; VEGF, vascular endothelial growth factor; XRT, external radiation therapy.

Table adapted with permission from Pollack M et al. Curr Med Res Opin. 2021;37(1):59-70.
In an initial analysis of 72 patients treated with larotrectinib who had received at least 1 prior line of systemic therapy, median GMI was 2.68 -more than double the 1.33 threshold for meaningful clinical activity suggested in the literature-with $65 \%$ of patients having a GMI of 1.3 or greater and $26 \%$ having a GMI of 5 or greater (Figure 1A). ${ }^{4}$ Nonparametric analysis adjusting for censored PFS durations indicated a 0.75 probability of GMI of at least 1.33, with Kaplan-Meier estimates demonstrating a median GMI of 6.46. Median PFS on larotrectinib was longer than TTP on the prior therapy (not estimable [NE] vs 3.0 months; HR, 0.220; 95\% CI, 0.146-0.332); this supported the GMI results. ${ }^{4}$ In a more recent expanded data set $(n=140)$ with additional follow-up, the Kaplan-Meier-estimated median GMI was 8.9. The majority (74\%) of patients met the GMI threshold of 1.33 or greater, regardless of age, tumor type, or prior number of therapies. Median PFS on larotrectinib was 33.0 months and median TTP on the prior therapy was 3.0 months (HR, 0.22; 95\% CI, 0.16-0.30).22

For entrectinib, GMI analyses were based on data from 71 adults with TRK fusion cancer treated during the single-arm phase 2 STARTRK-2 trial. Among patients who had progressed on prior therapy $(n=38)$, of the challenges associated with single-arm trials, which do not provide comparative data against a control. Using the GMI provides intrapatient comparative data using individual patients as their own control, thus generating comparative efficacy data for drugs developed in single-arm trials. The end point has been endorsed by the EMA for truly rare tumors or very narrow indications. ${ }^{28}$

GMI is the ratio of PFS on current therapy to time to progression (TTP) on the most recent prior line of therapy within the same patient. Since TTP typically decreases with each subsequent line of anticancer therapy, a GMI of greater than 1 would suggest that an investigational therapy is having a positive impact on a tumor's natural history. A GMI of 1.33 or greater indicates an improvement in PFS of at least 33\% over the previous line of therapy and has been proposed as a threshold of meaningful clinical activity. ${ }^{29}$ Separate retrospective exploratory GMI analyses have been performed to determine whether larotrectinib, entrectinib, or both provide clinical benefit vs prior standard-of-care treatment in patients with TRK fusion cancer. Findings from the 2 analyses suggest that both larotrectinib and entrectinib provide improved clinical outcomes in patients with TRK fusion cancer compared with prior therapies. , $5,22^{2}$ median GMI was 2.53 , with $65.8 \%$ of patients having a GMI ratio at least 1.3 (Figure 1B). ${ }^{5}$ The ORR was $60.5 \%$ for entrectinib vs $15.8 \%$ for prior therapy in this setting, and median PFS for entrectinib exceeded median time to discontinuation for prior therapy (11.2 vs 2.9 months). ${ }^{5}$

\section{Parametric Extrapolation-Based Comparisons}

For patients with locally advanced or metastatic radioactive iodine-refractory differentiated thyroid cancer, standard-of-care systemic therapies are the tyrosine kinase inhibitors sorafenib and lenvatinib. The long-term comparative effectiveness of larotrectinib vs these agents for radioactive iodine-refractory advanced thyroid cancer has been evaluated using partitioned survival models that estimate the proportion of patients in the preprogression and progression health states. In this analysis, larotrectinib was estimated to provide improved life-year outcomes compared with sorafenib and lenvatinib (Figure 2). ${ }^{30}$ In the base case, model-estimated mean preprogression life-years were 4.24 for larotrectinib, 1.35 for sorafenib, and 2.14 for lenvatinib; estimated mean total life-years were $6.32,5.47$, and 4.36 , respectively. Larotrectinib was also estimated 
to provide improved quality-adjusted life-year (QALY) outcomes compared with sorafenib and lenvatinib. Estimated mean preprogression QALYs were 3.57, 1.09, and 1.80, respectively; estimated mean total QALYs were 4.61, 3.15, and 2.91 , respectively. ${ }^{30}$ In this analysis, NTRK gene fusion status in patients receiving lenvatinib and sorafenib was unknown.

\section{Modeling the Comparative Effectiveness of Larotrectinib and Entrectinib}

To date, no study has compared larotrectinib with entrectinib for the treatment of solid tumors with NTRK gene fusions. Although these agents were both studied in similar basket trials, there are important differences between the larotrectinib and entrectinib clinical trial patient populations that make direct comparison of the 2 data sets challenging. ${ }^{11,31}$

\section{Matching-Adjusted Indirect Comparison}

The relative effectiveness of larotrectinib and entrectinib for the treatment of patients with TRK fusion cancer has been evaluated using a matching-adjusted indirect comparison. In this analysis, adult patients from larotrectinib clinical trials and from published aggregate entrectinib trial data were identified and matched based on available common baseline demographic and clinical characteristics that may be predictive of outcome (eg, gender, age, race, ECOG performance status, select tumor types, metastatic disease, NTRK gene, central nervous system metastases, number of prior lines of therapy). After matching, larotrectinib was associated with significantly longer OS compared with entrectinib: median not reached (95\% CI, 38.7 months to NE) vs 23.9 months ( $95 \% \mathrm{CI}, 16.0$ months to NE; $P<.05$ ). It was also associated with significantly longer DOR (median, 32.5 vs 12.9 months; $P<.05)$, whereas there was a numerical improvement in PFS with larotrectinib that was not statistically significant (median, 19.3 vs 11.2 months; $P=.07$ ). The ORR was similar for both drugs (67.3\% vs $63.5 \% ; P=.63$ ), but the rate of complete response was significantly greater with larotrectinib $(20.3 \%$ vs $6.8 \% ; P<.05) .{ }^{32}$

Larotrectinib and entrectinib have both been shown to be generally well tolerated in clinical trials. Dose reductions and treatment discontinuations due to treatment-related adverse events (TRAEs) occurred in $8 \%$ and $2 \%$ of patients receiving larotrectinib respectively, ${ }^{31}$ and in $27 \%$ and $4 \%$ of patients receiving entrectinib respectively. ${ }^{11}$ In a matching-adjusted indirect comparison, serious TRAEs occurred in $6.2 \%$ and $10.0 \%$ of patients receiving larotrectinib and entrectinib, respectively, and TRAEs leading to discontinuation occurred in $0.5 \%$ and $4.0 \%$ of patients. ${ }^{32}$

\section{Parametric Extrapolation-Based Comparisons}

In the absence of direct comparative studies or meta-analyses, simulation-based modeling, which extrapolates data from small clinical samples, may offer some insight into how larotrectinib and entrectinib compare and may help inform clinical and health care system reimbursement decision-making.

Roth and colleagues developed a partitioned survival model to project the long-term comparative effectiveness of 
FIGURE 2. Parametric Extrapolations of (A) PFS and (B) OS With Larotrectinib, Sorafenib, and Lenvatinib in Advanced Thyroid Cancer ${ }^{30}$

A

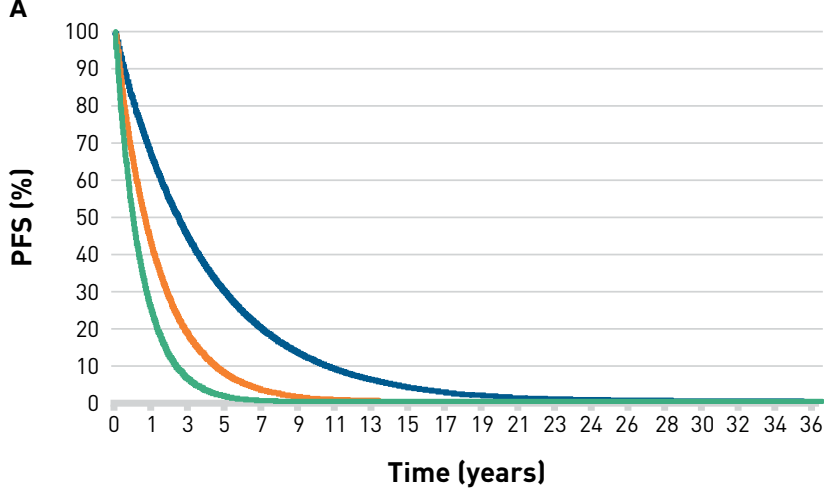

B

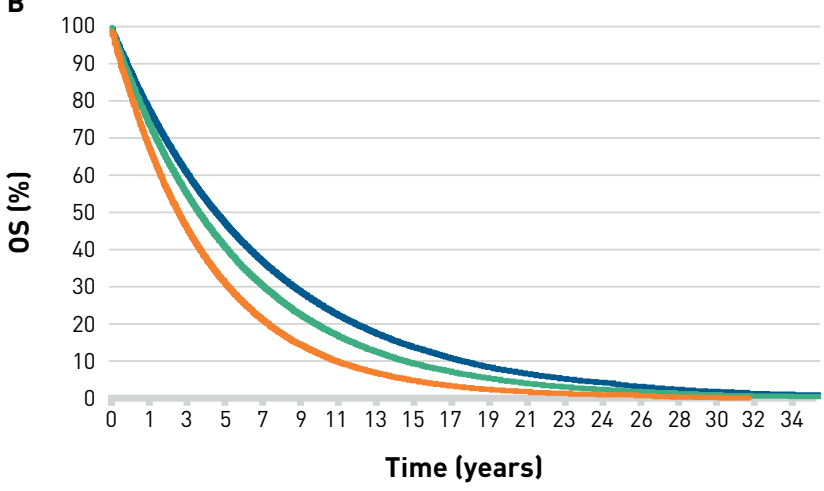

- Larotrectinib - Lenvatinib - Sorafenib

OS, overall survival; PFS, progression-free survival.

Figures reproduced with permission from Carlson JJ et al. Value Health. 2021;24(suppl 1):S20.

FIGURE 3. Parametric Extrapolations of PFS and OS With Larotrectinib and Entrectinib in TRK Fusion-Positive Non-Small Cell Lung Cancer ${ }^{33}$

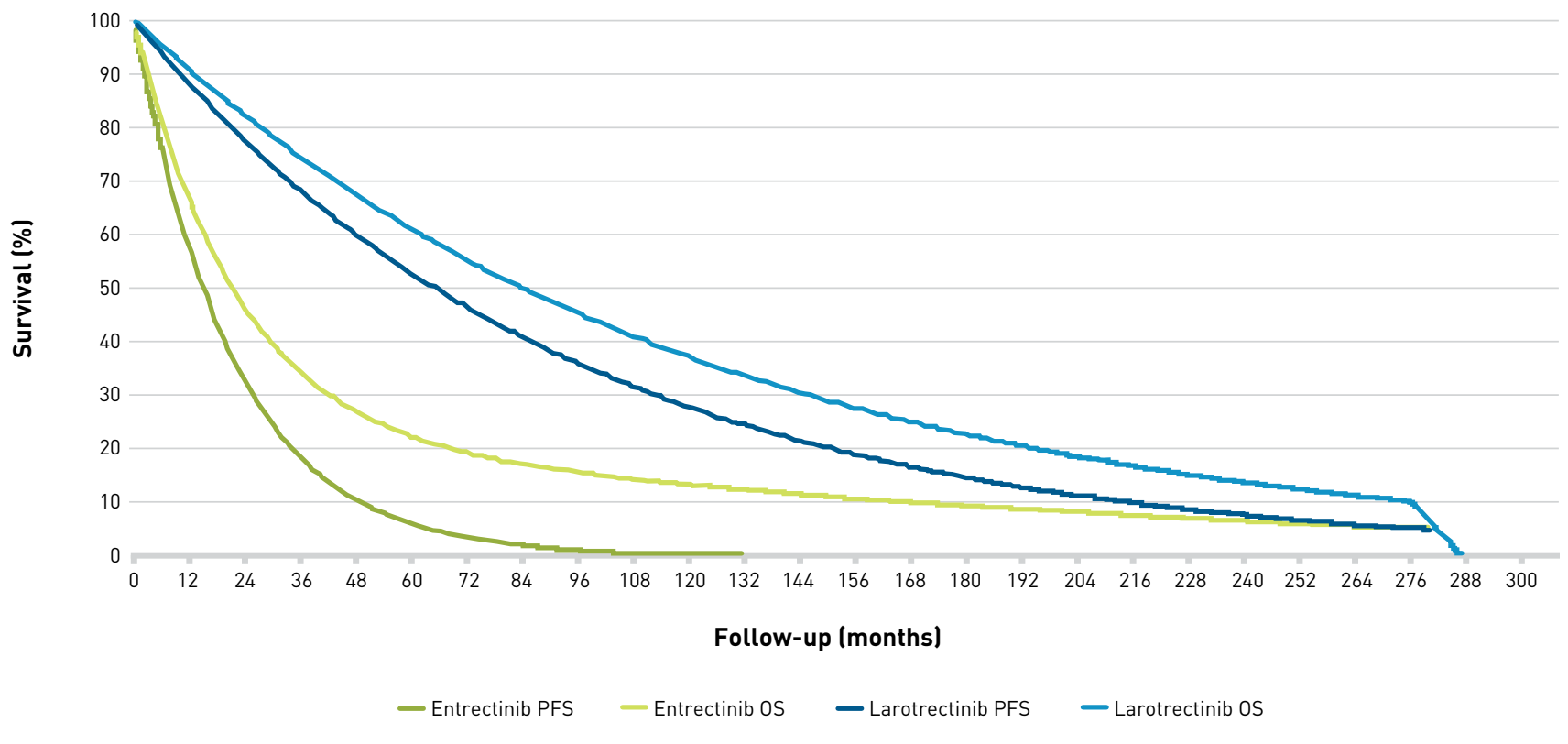

OS, overall survival; PFS, progression-free survival; TRK, tropomyosin receptor kinase.

Figure reproduced with permission from Roth JA et al. J Manag Care Spec Pharm. 2020;26(8):981-986.

larotrectinib vs entrectinib in second-line treatment of metastatic NSCLC. The authors performed parametric extrapolations of in-trial PFS and OS data (median follow-up, 13 months) from patients with TRK fusion-positive NSCLC treated with larotrectinib $(n=12)$ and entrectinib $(n=10)$ during single-arm phase $1 / 2$ studies. Larotrectinib was estimated to provide improved life-year outcomes compared with entrectinib (Figure 3) ${ }^{33}$ In the base case, modelestimated mean preprogression life-years were 7.5 for larotrectinib and 1.9 for entrectinib; estimated mean total life-years were 9.2 and 4.4, respectively. Larotrectinib was also estimated to provide improved QALY outcomes compared with entrectinib. Estimated mean preprogression QALYs were 5.0 and 1.2, respectively, with 
respective estimated mean total QALYs of 5.8 and 2.4. Sensitivity analyses indicated persistent gains for larotrectinib under a range of clinically plausible survival effects. ${ }^{33}$

This approach has also been used to model the comparative effectiveness of larotrectinib vs entrectinib in patients with TRK fusion-positive solid tumors with brain metastases. This analysis included 14 larotrectinib-treated patients (7 NSCLC, 4 thyroid cancer, 2 melanoma, 1 breast cancer) and 16 entrectinib-treated patients (8 NSCLC, 4 thyroid cancer, 2 sarcoma, 1 breast cancer, 1 salivary gland cancer). Larotrectinib was estimated to provide improved life-year outcomes compared with entrectinib in these patients. Estimated mean preprogression life-years were 1.91 for larotrectinib and 0.80 for entrectinib; mean total life-years were 2.76 and 1.66 , respectively. ${ }^{34}$

\section{Conclusions}

Regulatory acceptance of single-arm trial data led to the tumor-agnostic approvals of the TRK inhibitors larotrectinib and entrectinib for treatment of solid tumors harboring NTRK gene fusions. Historical and intrapatient comparisons, in addition to parametric extrapolation-based modeling, suggest that TRK inhibitors improve disease response and survival compared with non-TRK-targeted standard therapies across most tumor histologies. Matching-adjusted indirect comparison and simulation studies suggest greater benefit to survival outcomes with larotrectinib compared with entrectinib. Although limited due to the number of patients and lack of direct comparisons, these analyses provide some insight into the position of TRK inhibitors in established treatment paradigms in a setting where real-world evidence will be slow to gather due to the rare nature of these cancers. This carries importance because it is likely that patients will have only 1 opportunity to receive a first-generation TRK inhibitor before the development of resistance mutations, or other mechanisms of resistance, that a second first-generation TRK inhibitor would then be ineffective against.

\section{Acknowledgments}

Medical writing support was provided by Michael Sheldon, PhD, and editorial support was provided by George Chappell, MSc, both of Scion (London, UK), supported by Bayer according to Good Publication Practice guidelines. Bayer was involved in fact-checking information provided in the manuscript. However, ultimate responsibility for opinions, conclusions, and data interpretation lies with the authors.

Author affiliations: Thomas Jefferson University Hospitals (MSB); University of Washington (JJC, SDS); University of California, Los Angeles (NF); Institut Bergonié (AI); Oregon Health and Science University (SK); Rigshospitalet (UL); Fred Hutchinson Cancer Research Center (SDS).

Funding source: This article was published as part of a supplement that was financially supported by Bayer HealthCare Pharmaceuticals, Inc. Noah Federman's research is supported by NIH National Center for Advancing Translational Science (NCATS) UCLA Clinical \& Translational Science Institute (CTSI) Grant Number ULITRooi88I.

Author disclosures: Dr Brose, Dr Carlson, Dr Federman, Dr Kummar, Dr Lassen, and Dr Sullivan have been part of consultancies or paid advisory boards with Bayer. Dr Brose and Dr Federman have been part of consultancies or paid advisory boards with Loxo Oncology. Dr Brose has also been part of consultancies or paid advisory boards with Genentech, AstraZeneca, and Eli Lilly and Company. Dr Brose has received honoraria from Clinical Care Options, Medscape, Onclive ${ }^{\circledast}$, and PeerView. Dr Brose has also disclosed that research support to the University of Pennsylvania School of Pharmacy has been provided by Bayer, Loxo Oncology, Genentech, Eisai, Blueprint Medicines, Eli Lilly and Company, and Novartis. Dr Carlson has received honoraria from Adaptive Biotechnologies. Dr Federman has received lecture fees for speaking at the invitation of Bayer and received patent royalties from NanoValent Pharmaceuticals, Inc. Dr Federman has also disclosed that he holds stock in the for-profit health care companies Genmab, Reata Pharmaceuticals, and bluebird bio, Inc. Dr Italiano and Dr Lassen have both received grants from Roche. Dr Italiano has also received grants from AstraZeneca, Bayer, Merck, Merck Sharp \& Dohme, and PharmaMar. Dr Italiano has disclosed that he has received honoraria from Bayer, Daiichi Sankyo, Epizyme, Ipsen, Roche, and SpringWorks Therapeutics. Dr Kummar has been part of consultancies or paid advisory boards with Boehringer Ingelheim, SpringWorks Therapeutics, Gilead, EcoRi Capital, Seagen, Mundipharma, Mirati Therapeutics, Genome \& Company, and Harbour Biomed. Dr Kummar has also disclosed that she is the cofounder and is an equity holder for PathomIQ. Dr Kummar has also disclosed that she is the editor-in-chief of Current Problems in Cancer (Elsevier) and that her spouse is a scientific adviser for Cadila Pharmaceuticals Ltd and is the founder of Arxeon Inc. Dr Lassen has also reported that he has been part of consultancies or paid advisory boards with Pfizer and Novartis. Dr Lassen has also received grants from Bristol Myers Squibb, GlaxoSmithKline, and Pfizer.

Authorship information: Analysis and interpretation of data (JCC, AI, MSB, NF, UL, SK, SDS); drafting of the manuscript (JCC, AI, MSB, NF, UL, SK, SDS); critical revision of the manuscript for important intellectual content (JCC, AI, MSB, NF, UL, SK, SDS).

Address correspondence to: Josh J. Carlson, PhD, MPH; carlsojj@gmail.com

\section{REFERENCES}

1. Cocco E, Scaltriti M, Drilon A. NTRK fusion-positive cancers and TRK inhibitor therapy. Nat Rev Clin Oncol. 2018;15(12):731-747. doi:10.1038/s41571-018-0113-0

2. Amatu A, Sartore-Bianchi A, Bencardino K, Pizzutilo EG, Tosi F, Siena S. Tropomyosin receptor kinase (TRK) biology and the role of NTRK gene fusions in cancer. Ann Oncol. 2019;30(Suppl 8):viii5-viii15. doi:10.1093/annonc/mdz383

3. Federman N. McDermott R. Larotrectinib, a highly selective tropomyosin receptor kinase (TRK) inhibitor for the treatment of TRK fusion cancer. Expert Rev Clin Pharmacol. 2019:12(10):931-939. doi:10.1080/ 17512433.2019.1661775

4. Italiano A, Nanda S, Briggs A, et al. Larotrectinib versus prior therapies in tropomyosin receptor kinase fusion cancer: an intra-patient comparative analysis. Cancers (Basel). 2020;12(11):3246. doi:10.3390/ cancers12113246

5. Krebs MG, Blay J-Y, Le Tourneau C, et al. Intrapatient comparisons of efficacy in a single-arm trial of entrectinib in tumour-agnostic indications. ESMO Open. 2021;6(2):100072. doi:10.1016/j.esmoop.2021.100072 6. Pollack M, Keating K, Wissinger E, Jackson L, Sarnes E, Cuffel B. Transforming approaches to treating TRK fusion cancer: historical comparison of larotrectinib and histology-specific therapies. Curr Med Res Opin. 2021;37(1):59-70. doi:10.1080/03007995.2020.1847057

7. Bayer AG. Vitrakvi: annex I - summary of product characteristics. European Medicines Agency; updated May 2021. Accessed October 1, 2021. https://www.ema.europa.eu/en/documents/product-information/ vitrakvi-epar-product-information_en.pdf

8. Vitrakvi. Prescribing information. Bayer HealthCare Pharmaceuticals; updated March 2021. Accessed November 15, 2021. https://www.accessdata.fda.gov/drugsatfda_docs/label/2021/210861s006lbl.pdf 9. Rozlytrek. Prescribing information. Genentech; updated November 2021. Accessed November 15, 2021. https://www.gene.com/download/pdf/rozlytrek_prescribing.pdf

10. Roche Pharma AG. Rozlytrek: annex I - summary of product characteristics. European Medicines Agency; updated September 2021. Accessed October 1, 2021. https://www.ema.europa.eu/en/documents/ product-information/rozlytrek-epar-product-information_en.pdf

11. Doebele RC, Drilon A, Paz-Ares L, et al; trial investigators. Entrectinib in patients with advanced or metastatic NTRK fusion-positive solid tumours: integrated analysis of three phase 1-2 trials. Lancet Oncol. 2020;21(2):271-282. doi:10.1016/S1470-2045(19)30691-6

12. Drilon A, Laetsch TW, Kummar S, et al. Efficacy of larotrectinib in TRK fusion-positive cancers in adults and children. N Engl J Med. 2018:378(8):731-739. doi:10.1056/NEJMoa1714448

13. Robinson GW, Gajjar AJ, Gauvain KM, et al. Phase 1/1B trial to assess the activity of entrectinib in children and adolescents with recurrent or refractory solid tumors including central nervous system (CNS) tumors. J Clin Oncol. 2019:37(suppl 15):abstr 10009. doi:10.1200/JC0.2019.37.15_suppl.10009 14. Cardoso F, Paluch-Shimon S, Senkus E, et al. 5th ESO-ESMO international consensus guidelines for advanced breast cancer (ABC 5). Ann Oncol. 2020;31(12):1623-1649. doi:10.1016/j.annonc.2020.09.010 15. Planchard D, Popat S, Kerr K, et al; ESMO Guidelines Committee. Metastatic non-small cell lung cancer: ESMO Clinical Practice Guidelines for diagnosis, treatment and follow-up. Ann Oncol. 2018;29(suppl 4):iv192-iv237. doi:10.1093/annonc/mdy275 
16. Filetti S, Durante C, Hartl D, et al; ESMO Guidelines Committee. Thyroid cancer: ESMO Clinical Practice Guidelines for diagnosis, treatment and follow-up. Ann Oncol. 2019;30(12):1856-1883. doi:10.1093/annonc/mdz400

17. Geiger JL, Ismaila N, Beadle B, et al. Management of salivary gland malignancy: ASCO Guideline. J Clin Oncol. 2021:39(17):1909-1941. doi:10.1200/JC0.21.00449

18. Gronchi A, Miah AB, Dei Tos AP, et al. ESMO Guidelines Committee, EURACAN and GENTURIS. Soft tissue and visceral sarcomas: ESMO-EURACAN-GENTURIS Clinical Practice Guidelines for diagnosis, treatment and follow-up. Ann Oncol. 2021;32(11):1348-1365. doi:10.1016/j.annonc.2021.07.006

19. Hanna NH, Robinson AG, Temin S, et al. Therapy for stage IV non-small-cell lung cancer with driver alterations: ASCO and OH (CCO) Joint Guideline update. J Clin Oncol. 2021;39(9):1040-1091. doi:10.1200/JC0.20.03570 20. Cocco E, Schram AM, Kulick A, et al. Resistance to TRK inhibition mediated by convergent MAPK pathway activation. Nat Med. 2019:25(9):1422-1427. doi:10.1038/s41591-019-0542-z

21. Drilon A, Ou S-HI, Cho BC, et al. Repotrectinib (TPX-0005) is a next-generation ROS1/TRK/ ALK inhibitor that potently inhibits ROS1/TRK/ALK solvent-front mutations. Cancer Discov. 2018:8(10):1227-1236. doi:10.1158/2159-8290.CD-18-0484

22. Hong DS, Italiano A, Briggs A, et al. Intra-patient comparison from larotrectinib clinical trials in TRK fusion cancer: an expanded dataset. J Clin Oncol. 2021;39(suppl 15):abstr 3114. doi:10.1200/ JC0.2021.39.15 suppl.3114

23. Desai AV, Robinson GW, Basu EM, et al. Updated entrectinib data in children and adolescents with recurrent or refractory solid tumors, including primary CNS tumors. J Clin Oncol. 2020;38(suppl 15):abstr 107. doi:10.1200/JCO.2020.38.15 suppl.107

24. Park IH, Lee KS, Ro J. Effects of second and subsequent lines of chemotherapy for metastatic breast cancer. Clin Breast Cancer. 2015;15(1):e55-62. doi:10.1016/j.clbc.2014.09.001

25. Tournigand C, André T, Achille E, et al. FOLFIRI followed by FOLFOX6 or the reverse sequence in advanced colorectal cancer: a randomized GERCOR study. J Clin Oncol. 2004;22(2):229-237. doi:10.1200/JC0.2004.05.113
26. Bazhenova L, Lokker A, Snider J, et al. TRK fusion cancer: patient characteristics and survival analysis in the real-world setting. Target Oncol. 2021;16(3):389-399. doi:10.1007/s11523-021-00815-4 27. Bridgewater J, Jiao X, Parimi M, et al. Abstract 394: prognosis and molecular characteristics of patients with TRK fusion cancer in the 100,000 Genomes Project. Cancer Res. 2021;81(13 suppl). doi:10.1158/1538-7445.AM2021-394

28. Guideline on the evaluation of anticancer medicinal products in man. European Medicines Agency. September 22, 2017. Accessed September 9, 2019. https://www.ema.europa.eu/en/documents/scientificguideline/guideline-evaluation-anticancer-medicinal-products-man-revision-5_en.pdf

29. Von Hoff DD. There are no bad anticancer agents, only bad clinical trial designs-twenty-first Richard and Hinda Rosenthal Foundation Award Lecture. Clin Cancer Res. 1998;4(5):1079-1086.

30. Carlson JJ, Suh K, Xia F, Williamson T, Sullivan SD. PCN11 The potential long-term comparative effectiveness of larotrectinib vs. lenvatinib or sorafenib for treatment of NTRK fusion-positive metastatic thyroid cancer. Value Health. 2021;24(suppl 1):S20. doi:10.1016/j.jval.2021.04.103

31. Hong DS, DuBois SG, Kummar $S$, et al. Larotrectinib in patients with TRK fusion-positive solid tumours: a pooled analysis of three phase 1/2 clinical trials. Lancet Oncol. 2020;21(4):531-540. doi:10.1016/S1470-2045(19)30856-3

32. Garcia-Foncillas J, Bokemeyer C, Italiano A, et al. 104P Matching-adjusted indirect comparison for treatment of NTRK fusion cancer with larotrectinib versus entrectinib. Ann Oncol. 2021;32(suppl 5):S401. doi:10.1016/j.annonc.2021.08.384

33. Roth JA, Carlson JJ, Xia F, Williamson T, Sullivan SD. The potential long-term comparative effectiveness of larotrectinib and entrectinib for second-line treatment of TRK fusion-positive metastatic lung cancer. J Manag Care Spec Pharm. 2020;26(8):981-986. doi:10.18553/jmcp.2020.20045

34. Suh K, Carlson JJ, Xia F, Williamson T, Sullivan SD. C35 A comparison of extrapolated survival estimates for larotrectinib vs entrectinib in NTRK fusion-positive patients with brain metastasis. J Manag Care Spec Pharm. 2021;27(suppl 10a):S31. doi:10.18553/jmcp.2021.27.issue-10-a 


\title{
SUPPLEMENT POLICY STATEMENT
}

\author{
Standards for Supplements to The American Journal of Managed Care ${ }^{\circledR}$
}

All supplements to The American Journal of Managed Care ${ }^{\circledR}$ are designed to facilitate and enhance ongoing medical education in various therapeutic disciplines. All Journal supplements adhere to standards of fairness and objectivity, as outlined below. Supplements to The American Journal of Managed Care ${ }^{\circledR}$ will:

I. Be reviewed by at least 1 independent expert from a recognized academic medical institution.

II. Disclose the source of funding in at least 1 prominent place.

III. Disclose any existence of financial interests of supplement contributors to the funding organization.

IV. Use generic drug names only, except as needed to differentiate between therapies of similar class and indication.

V. Be up-to-date, reflecting the current las of date of publication) standard of care.

VI. Be visually distinct from The American Journal of Managed Care ${ }^{\circledR}$.

VII. Publish information that is substantially different in form and content from that of the accompanying edition of The American Journal of Managed Care ${ }^{\circledR}$.

VIII. Prohibit excessive remuneration for contributors and reviewers.

IX. Carry no advertising.

Publisher's Note: The opinions expressed in this supplement are those of the authors, presenters, and/or panelists and are not attributable to the sponsor or the publisher, editor, or editorial board of The American Journal of Managed Care ${ }^{\circledR}$. Clinical judgment must guide each professional in weighing the benefits of treatment against the risk of toxicity. Dosages, indications, and methods of use for products referred to in this supplement are not necessarily the same as indicated in the package insert for the product and may reflect the clinical experience of the authors, presenters, and/or panelists or may be derived from the professional literature or other clinical sources. Consult complete prescribing information before administering. 
